\title{
Adjustable polystyrene nanoparticle templates for the production of mesoporous foams and $\mathrm{ZnO}$ inverse opals
}

\author{
Karina Abitaev ${ }^{1} \cdot$ Yaseen Qawasmi $^{1} \cdot$ Petia Atanasova $^{2} \cdot$ Carina Dargel $^{3} \cdot$ Joachim Bill $^{2}$ - Thomas Hellweg ${ }^{3}$. \\ Thomas Sottmann ${ }^{1}$
}

Received: 3 September 2020 / Revised: 9 November 2020 / Accepted: 23 November 2020 / Published online: 5 December 2020

(C) The Author(s) 2020

\begin{abstract}
The manifold applications of porous materials, such as in storage, separation, and catalysis, have led to an enormous interest in their cost-efficient preparation. A promising strategy to obtain porous materials with adjustable pore size and morphology is to use templates exhibiting the appropriate nanostructure. In this study, close-packed polystyrene (PS) nanoparticles, synthesized by emulsion polymerization, were used to produce porous PS and $\mathrm{ZnO}$ inverse opals. The size and distribution of the polystyrene nanoparticles, characterized by dynamic light scattering (DLS), small-angle neutron scattering (SANS), and scanning electron microscopy (SEM), were controlled via the concentration of sodium dodecyl sulfate (SDS). Systematic measurements of the water/ styrene-interfacial tension show that the critical micelle concentration (CMC) of the ternary water-styrene-SDS system, which determines whether monodisperse or polydisperse PS particles are obtained, is considerably lower than that of the binary waterSDS system. The assemblies of close-packed PS nanoparticles obtained via drying were then studied by small-angle X-ray scattering (SAXS) and SEM. Both techniques prove that PS nanoparticles synthesized above the CMC result in a significantly unordered but denser packing of the particles. The polystyrene particles were subsequently used to produce porous polystyrene and $\mathrm{ZnO}$ inverse opals. While the former consists of micrometer-sized spherical pores surrounded by extended open-cellular regions of mesopores $\left(R_{\text {pore }} \approx 25 \mathrm{~nm}\right.$ ), the latter are made of $\mathrm{ZnO}$-nanoparticles forming a structure of well-aligned interconnected pores.
\end{abstract}

Keywords Emulsion polymerization $\cdot$ Critical micelle concentration $\cdot$ Porous polystyrene $\cdot$ Inverse opals $\cdot$ SANS $\cdot$ SAXS $\cdot$ SEM

\section{Introduction}

Hierarchically structured assemblies of uniform spherical polymer particles have attracted considerable attention due to their variety of applications that range from photonic

Thomas Sottmann

thomas.sottmann@ipc-uni-stuttgart.de

Joachim Bill

joachim.bill@imw.uni-stuttgart.de

Thomas Hellweg

thomas.hellweg@uni-bielefeld.de

1 Institute of Physical Chemistry, University of Stuttgart, Stuttgart, Germany

2 Department for Materials Science, University of Stuttgart, Stuttgart, Germany

3 Department of Physical and Biophysical Chemistry, Bielefeld University, Bielefeld, Germany bandgap crystals [1-3] to masks in lithography [4-7] as well as templates for the preparation of highly ordered porous organic and inorganic materials [8-10]. However, the building blocks of these assemblies are not limited to spherical particles, for instance, non-spherical particles [11, 12], core-shell and hollow spheres [13, 14], Janus-like particles [15, 16], and stimuli-responsive particles $[17,18]$ were successfully used as well. Assembling the building blocks by various techniques, yields 2D films and 3D-ordered structures. For more details, we refer the interested reader to some recent reviews [19-21].

Among the porous materials synthesized by using a wellstructured template are oxide inverse opals with sensing, photonic or semiconducting properties [22-24]. Oxide inverse opals are prepared either by co-assembly of polymer and inorganic particles or by infiltration of the polymer colloidal crystal templates with oxide precursor solutions, which are subsequently mineralized. These organic/inorganic hybrids are then calcinated or the polymer particles are removed with an appropriate organic solvent and the corresponding porous inverse replica is formed. Recently, Strey and Müller have introduced 
the so-called nanofoams by continuity inversion of dispersion (NF-CID) principle where colloidal crystal-like structures of thermoplastic polymer particles are transferred into a porous polymer using a supercritical (sc-) blowing agent, e.g., $\mathrm{CO}_{2}$ $[25,26]$. In contrast to an approach where thin films of nanofoam are obtained from foaming thin polymer films after several hours of saturation with sc- $\mathrm{CO}_{2}[27,28]$, the saturation time is considerably reduced to seconds due to the enormous surface area of the colloidal crystal-like structures made of nanoparticles [29]. As the polymer nanoparticles are saturated by the sc-blowing agent, their glass transition temperature $T_{\mathrm{g}}$ is reduced $[30,31]$. A temperature increase above the reduced glass transition temperature $T_{\mathrm{g}}$ * initiates an inversion of the particles towards a viscous polymer matrix. The voids between the polymer nanoparticles transform into a high number density of spherical sc-blowing agent-filled nanodroplets in the viscous polymer matrix. The subsequent foaming is initiated by a pressure release above the critical temperature of the sc-fluid which induces the gradual transition of each nanodroplet into a foam bubble. Simultaneously, the polymer matrix is fixed due to the diffusion of sc-fluid molecules out of the matrix and the related increase of $T_{\mathrm{g}}{ }^{*}$. Finally, a nanoporous polymer is obtained which can be used in heat insulation [32,33], gas storage [34], separation [35], and catalysis [36]. Using the porous polymer as a template itself, Qawasmi et al. [37] have mineralized porous polystyrene (PS), previously prepared by the NF-CID method, at mild conditions via chemical bath deposition (CBD) with a $\mathrm{ZnO}$ precursor solution. A metal oxide layer on the pore wall was formed, while the porous structure was preserved. The obtained porous organic/inorganic $(\mathrm{PS} / \mathrm{ZnO})$ hybrid material showed higher mechanical stability than the original porous PS, making them more applicable in different fields like for instance as solid support in heterogeneous catalysis.

According to the template strategy, the structure of the porous materials should be closely related to the template structure. Thus, using colloidal crystal-like structures as templates the pore size and morphology are expected to be closely related to the size and polydispersity of the polymer particles as well as their packing in the close-packed assembly. Synthesizing polymer particles by emulsion polymerization allows tuning the particle properties by the variation of the reaction conditions, such as the temperature [38], the initiator [39], or the surfactant concentration [40]. Thereby, the latter parameter might have the largest influence on the particle size. The strong decrease of the particle size generally found with surfactant concentration is usually attributed to an enhanced stabilization of newly formed primary polymer particles by surfactant molecules which slows down the particle growth by coagulation $[41,42]$. This trend is known to change when micelles are formed exceeding the critical micelle concentration (CMC) and attributed to the appearance of micellar nucleation processes [43-45]. The predominant particle formation mechanism switches from a homogeneous nucleation mechanism [46-48] at surfactant concentrations below the $\mathrm{CMC}$ towards a mixed mode of particle nucleation, i.e., homogeneous vs. micellar, above the CMC [49]. While most of the studies relate this change in nucleation mechanism to the CMC of the respective binary water-surfactant-systems, Farías-Cepeda et al. [50] found indications that instead the $\mathrm{CMC}$ of the polymerizable system determines the concentration where the mixed mode of particle nucleation occurs. It is interesting to note that the size of microgel particles is constant above the CMC, but is linearly dependent on the surfactant concentration below the CMC [51]. However, the polydispersity does not seem to depend on the addition of surfactant.

Although the CMC of many binary water-surfactant mixtures, like water-sodium dodecyl sulfate (SDS) [52] are wellknown, there are only a few data for systems of the type water-styrene-SDS used in emulsion polymerization. Harada et al. [53] $\left(1.7 \mathrm{mM}\right.$ at $\left.50{ }^{\circ} \mathrm{C}\right)$ and Hansen and Ugelstad [54] $\left(5.3 \mathrm{mM}\right.$ at $\left.60^{\circ} \mathrm{C}\right)$ have shown that the presence of styrene and salts reduces the CMC of the corresponding water-SDS system (9.4 mM and $10.8 \mathrm{mM}$, respectively [52]) using the Du Noüy ring method. In contrast to them, Chang et al. [55] reported an increase of the water-styrene-SDS $\mathrm{CMC}$ at $25^{\circ} \mathrm{C}$ as determined by the pendant drop technique $(6.7 \mathrm{mM})$ as well as conductivity measurements $(7.5 \mathrm{mM})$ compared to water-SDS (3.0 mM [56]). Farías-Cepeda et al. [50] reported at $70{ }^{\circ} \mathrm{C}$ a CMC of $5.3 \mathrm{mM}$ replacing styrene with ethylbenzene, also using the Du Noüy ring method. Furthermore, their results indicate that the polydispersity of the final polymer particles becomes significantly larger at the $\mathrm{CMC}$ of the ternary emulsion system. Using monomerstarved conditions [57] the polydispersity of the final dispersion was shown to be less pronounced. In contrast to classical emulsion polymerization, where all the monomer is placed in the reactor, monomer-starved semibatch emulsion polymerization is typically characterized by a continuous addition of the monomer to an existing dispersion of well-defined seed [58] particles or monomer [59, 60]. Note that this method also allows the synthesis of core-shell particles [61, 62].

The overall goal of this work was to use close-packed assemblies of polymer nanoparticles as templates for the preparation of $\mathrm{ZnO}$ inverse opals and mesoporous polystyrene refining the NF-CID principle $[25,26]$. Accordingly, the first part of this paper deals with the synthesis of polystyrene particles with adjustable size and polydispersity by emulsion polymerization. The structure of the PS particles synthesized at different SDS concentrations was characterized quantitatively by means of dynamic light scattering (DLS) and small-angle neutron scattering (SANS). In order to prove that the particle properties are related rather to the micellization in the ternary system water-styrene-SDS than to the micellization in the binary system water-SDS, we determined the CMC and its temperature dependence with the spinning drop method. The close-packed assemblies of polymer nanoparticles obtained 
by drying were studied by small-angle X-ray scattering (SAXS) as well as scanning electron microscopy (SEM). In the second part, the close-packed particle assemblies were foamed to obtain porous polymers. The modification of the NF-CID principle $[25,26]$ resulted in the preparation of a highly porous material consisting of micrometer-sized spherical pores surrounded by extended open-cellular regions of mesopores. In another approach, the voids of close-packed particle assemblies were mineralized with $\mathrm{ZnO}$ via the chemical bath deposition (CBD) method [63] to uniformly cover the PS-particles with $\mathrm{ZnO}$-nanoparticles and prepare a $\mathrm{ZnO}$ inverse opal via calcination of the $\mathrm{PS} / \mathrm{ZnO}$ hybrid structure.

\section{Experimental}

\section{Nanoparticle synthesis}

The polystyrene nanoparticles were synthesized via emulsion polymerization under nitrogen atmosphere. Double-distilled, degassed water $(180 \mathrm{~mL})$, and the respective amount of sodium dodecyl sulfate (purity $>99 \%$, Sigma-Aldrich) were placed in a three-necked round bottom flask, equipped with a reflux condenser, a magnetic stirrer, and a gas inlet. After the mixture was heated to $80{ }^{\circ} \mathrm{C}$, while constantly stirred at $750 \mathrm{rpm}$, a solution of styrene $(21 \mathrm{~mL}, 0.18 \mathrm{~mol},>99 \%$, Sigma-Aldrich) and the chain transfer agent 2-ethyl hexyl thioglycolate $(0.5 \mathrm{~mol} \%$ based on styrene, $>95 \%$, SigmaAldrich) were added to the aqueous surfactant mixture and allowed to equilibrate for $10 \mathrm{~min}$. Subsequently, potassium peroxydisulfate $(0.13 \mathrm{~g}, 0.047 \mathrm{mmol},>99 \%$, SigmaAldrich,) dissolved in double-distilled, degassed water $(10 \mathrm{~mL})$ was added to initiate the polymerization. Temperature and stirring speed were kept constant for additional $4.5 \mathrm{~h}$. Finally, the dispersion was filtered and dried in a crystallizing dish which was placed on a shaker plate at $40 \mathrm{rpm}$ (Model 3500 Advanced Shaker, VWR) at ambient temperature and pressure.

\section{Interfacial tension measurements}

The interfacial tension between aqueous SDS solutions (exhibiting different [SDS]) and styrene was measured at $25{ }^{\circ} \mathrm{C}, 30{ }^{\circ} \mathrm{C}, 45{ }^{\circ} \mathrm{C}$, and $60{ }^{\circ} \mathrm{C}$ using the spinning drop tensiometer SVT 15 from DataPhysics (Filderstadt, Germany). A droplet of styrene was introduced in the capillary filled with the respective aqueous SDS solution. After that, a rotation speed of 10,000 rpm was set and the formed droplets were analyzed with the Laplace-Young Fit [64] using the densities of styrene determined with the density meter DMA $5000 \mathrm{M}$ from Anton Paar (Graz, Austria), while the density of water is used for aqueous SDS solutions.

\section{Foaming}

The close-packed PS nanoparticles (obtained via drying) were foamed with supercritical $\mathrm{CO}_{2}$ using a home-built high-pressure sapphire cell [65]. The central part of the cell is a sapphire cylinder $\left(h=50 \mathrm{~mm}, \varnothing_{\text {Inside }}=10 \mathrm{~mm}, \varnothing_{\text {Outside }}=32 \mathrm{~mm}\right)$ with a sample volume of about $3 \mathrm{~mL}$. At the top, a piston seals the pressure cell and allows adjusting the sample volume and pressure. The pressure is measured by a miniature pressure transducer (Type 8530, Burster, Germany), placed in a casing at the bottom of the cell. By transferring the pressure cell into a thermostated water bath, where the temperature can be adjusted between $5^{\circ} \mathrm{C}$ and $80^{\circ} \mathrm{C}$ with an accuracy of $\Delta T= \pm 0.1 \mathrm{~K}$.

For foaming, a piece of the close-packed PS nanoparticles assemblies (approx. $0.5 \mathrm{~cm} \times 0.5 \mathrm{~cm} \times 0.5 \mathrm{~cm}(\mathrm{~W} \times \mathrm{H} \times \mathrm{D})$ ) was put on a sample holder in the high-pressure cell. After filling the cell with liquid $\mathrm{CO}_{2}$ at room temperature and $72 \mathrm{bar}$ using a home-built filling apparatus consisting of a membrane accumulator, the cell was transferred to a thermostated water bath, setting the temperature to $T=55^{\circ} \mathrm{C}$ and the pressure to $p=250$ bar. Unless otherwise stated, the pressure was released after an exposure time of $15 \mathrm{~min}$ by opening the valve rapidly.

\section{Preparation of $\mathrm{ZnO}$ inverse opals}

\section{$\mathrm{ZnO}$ inverse opals}

The $\mathrm{ZnO}$ deposition was conducted according to a procedure described in detail elsewhere [37]. Briefly, stock methanol solutions of $\mathrm{Zn}\left(\mathrm{OOCCH}_{3}\right)_{2} \cdot 2 \mathrm{H}_{2} \mathrm{O}\left(\mathrm{ZnAc}_{2}\right)(34 \mathrm{mM}$, SigmaAldrich), tetraethylammonium hydroxide (TEAOH) $(75 \mathrm{mM}$, Aldrich Chemistry), and polyvinylpyrrolidone (PVP) (21.7 mM, Sigma-Aldrich, $\mathrm{M}_{\mathrm{w}}=10,000$, Lot \# BCBJ4889V) were used to prepare the final precursor solution with a volume ratio 1:1:1 ( $\mathrm{ZnAc}_{2}$ :TEAOH:PVP). Closepacked monodisperse PS particles with a radius of $R=$ $113 \mathrm{~nm}$ and a polydispersity of $p=0.02$ were subjected to mineralization in vessels with aliquots of the precursor solution containing 2 vol. $\% \mathrm{H}_{2} \mathrm{O}$ at $60{ }^{\circ} \mathrm{C}$ for $1.5 \mathrm{~h}$ (1 deposition cycle). Subsequently, the substrates were thoroughly rinsed with methanol, dried under inert gas, and the next deposition cycle was executed. After 5 deposition cycles, the PS/ZnO hybrid structures were calcinated at $500{ }^{\circ} \mathrm{C}$ for $3 \mathrm{~h}$.

\section{Characterization}

\section{Dynamic light scattering}

The hydrodynamic radius of the polymer particles was determined with the 3D LS Spectrometer from LS Instruments (Fribourg, Switzerland) equipped with a high-performance DPL laser from Cobolt $(\lambda=561 \mathrm{~nm})$. Particle dispersions of $\sim 10 \mathrm{wt} \%$ were diluted with double-distilled water to 
$\sim 0.1 \mathrm{wt} \%$ and studied by varying the scattering angle between $30^{\circ}$ and $130^{\circ}$ in steps of $20^{\circ}$ at a temperature of $25^{\circ} \mathrm{C}$. The received time-intensity correlation functions were analyzed using CONTIN [66].

\section{Small-angle neutron scattering}

Neutron scattering experiments were performed at the D11 spectrometer at the Institute Laue-Langevin (ILL) in Grenoble (France) and at the KWS-1 spectrometer at the Heinz-MaierLeibnitz Zentrum (MLZ) in Munich (Germany). At D11, the neutron wavelength was set to $\lambda=5.5 \AA$ with a wavelength spread of $\Delta \lambda / \lambda=9 \%$ (FWHM). The detector/collimation distances of $39 / 40.5,8 / 8$, and $1.5 / 20.5 \mathrm{~m}$ yielded a $q$-range from 0.0015 to $0.4696 \AA^{-1}$, where $q=4 \pi \sin (\theta / 2) / \lambda$ is the absolute value of the scattering vector. For KWS-1, neutron wavelengths of $\lambda=5.0 \AA$ and $10 \AA$ with a wavelength spread of $\Delta \lambda / \lambda=$ $10 \%$ (FHWM) were used. Adjusting detector/collimation distances $20 / 20 \mathrm{~m}, 8 / 20 \mathrm{~m}$, and $1.5 / 8 \mathrm{~m}$ a $q$-range from 0.0013 to $0.5306 \AA^{-1}$ was accessible.

Aqueous dispersions of polystyrene particles $(\sim 10 \mathrm{wt} \%)$ was diluted to $\sim 0.1 \mathrm{wt} \%$ using $\mathrm{D}_{2} \mathrm{O}$ (>99\%, Eurisotop) and filled into Hellma quartz QS glass cells with an optical path length of $1 \mathrm{~mm}$. The cells were then placed in a home-built cell holder recording the scattering data at $25{ }^{\circ} \mathrm{C}$ using ${ }^{3} \mathrm{He}$ multiwire proportional chamber detectors at both facilities. For the raw data treatment, the software LAMP [67] and qtiSAS provided by the ILL and JCNS respectively were used, including the subtraction of dark current and the empty cell scattering, masking, and radial averaging, as well as the consideration of the sample transmission and the detector dead time. In order to normalize the data to absolute scale, the incoherent scattering of the second calibration standards $\mathrm{H}_{2} \mathrm{O}$ (ILL) and Perspex (MLZ) with optical path lengths of $1 \mathrm{~mm}$ and $1.5 \mathrm{~mm}$ were used, respectively. The analysis of the scattering data was performed using SasView (version 4.2.2).

\section{Small-angle X-ray scattering}

The dried, close-packed PS nanoparticles were analyzed by SAXS using a XEUSS SAXS/WAXS system from Xenocs (Grenoble, France). The instrument is equipped with a $\mathrm{CuK} \alpha$ source $(\lambda=1.541 \AA$, GeniX ultra-low divergence, Xenocs) and a Pilatus $300 \mathrm{~K}$ hybrid pixel detector (Dectris). A fine powder of the dried particles was captured between two Kapton® stripes of $1 \mathrm{~mm}$ thickness in a home-built cell holder. The measurements were performed at room temperature and a sample-to-detector distance of $2.7 \mathrm{~m}$, which allowed to investigate a $q$-range of $0.0043-0.1300 \AA^{-1}$. The raw data treatment was performed using the evaluation software Foxtrot [68] assuming close-packed particle assemblies, the measurement time, the transmission, and the background scattering. Finally, the data was normalized using glassy carbon type 2 [69] as standard. The analysis of the scattering data was performed using Sasfit (version 0.94.11).

\section{Scanning electron microscopy}

SEM analysis of the polymer particles and the porous polymers was performed using the Gemini SEM 500 from Carl Zeiss Microscopy (Jena, Germany) at $3 \mathrm{kV}$. Prior to the analysis of the porous polymers, the samples were freeze-fractured with liquid nitrogen to allow the investigation of freshly broken sharp edges. The samples were placed on a sample holder using silver lacquers (G3692, Plano GmbH, Wetzlar, Germany) and sputtered with a thin $10 \mathrm{~nm}$ layer of iridium. $\mathrm{ZnO}$ inverse opals were sputtered with $6 \mathrm{~nm}$ iridium and imaged at $1.7 \mathrm{kV}$.

SEM images were analyzed with respect to the particle size and polydispersity using the software ImageJ evaluating at least 150 particles or pores. By describing the size distribution with a Gaussian function, the mean radius $R_{\mathrm{SEM}}$ and the standard deviation $\sigma$ were received.

\section{Results and discussion}

In this work, we show that the expertise in synthesizing polystyrene (PS) nanoparticles of adjustable properties can be used to prepare highly porous materials. Accordingly, the first part deals with the correlation between the surfactant concentration applied in the emulsion polymerization and the size and polydispersity of the obtained polystyrene nanoparticles. Studying the interfacial tension between water/sodium dodecyl sulfate and styrene allowed us to link the increase in particle polydispersity to competing nucleation and growth mechanisms occurring at concentrations above the critical micelle concentration (CMC) of the ternary system. Drying resulted in closepacked PS nanoparticles assemblies, characterized by smallangle X-ray scattering (SAXS) and scanning electron microscopy (SEM). In the second part of this work, these dried assemblies of PS nanoparticles are then used for the preparation of porous polymers and $\mathrm{ZnO}$ inverse opals. While the former were obtained using the nanofoams by continuity inversion of dispersion (NF-CID) procedure [12, 13] and its further optimization, the latter were obtained via the chemical bath deposition (CBD) [63] method.

\section{Synthesis of PS particles of adjustable size and polydispersity}

The polystyrene nanoparticles used later on to prepare porous polymers and $\mathrm{ZnO}$ inverse opals were synthesized by emulsion polymerization at $80{ }^{\circ} \mathrm{C}$ using potassium peroxydisulfate as initiator and sodium dodecyl sulfate (SDS) as surfactant. To study the role of the surfactant concentration on the particle 
size and size distribution, the particle synthesis was performed at various SDS concentrations between $0 \mathrm{mM}$ and $26.2 \mathrm{mM}$, while the other process parameters were kept constant. Subsequently, the obtained particle dispersions were characterized by studying diluted samples with dynamic light scattering (DLS) and small-angle neutron scattering (SANS). Furthermore, scanning electron microscopy (SEM) was used to image the close-packed assemblies of the PS nanoparticles obtained via drying.

SANS curves of polystyrene nanoparticle dispersions synthesized at $[\mathrm{SDS}]=6.5 \mathrm{mM}, 7.5 \mathrm{mM}, 8.0 \mathrm{mM}, 8.5 \mathrm{mM}$, $9.0 \mathrm{mM}$, and $11.0 \mathrm{mM}$ were recorded at $T=25^{\circ} \mathrm{C}$. In order to increase the contrast while diminishing particle-particle interactions, the aqueous dispersions $(\sim 10 \mathrm{wt} \%)$ were diluted to $\sim 0.1 \mathrm{wt} \%$ via the addition of $\mathrm{D}_{2} \mathrm{O}$. The obtained coherent SANS intensities $I(q)$ were plotted as a function of the scattering vector $q$ in Fig. 1 using a double logarithmic representation. As can be seen, the curves show the typical features expected for the scattering of slightly polydisperse spherical objects in the limit of low number density $n$. At low $q$, a relatively high but almost constant intensity is observed. With increasing $q$, the intensity starts to decrease steeply until the first minimum is observed at intermediate $q$-values. The position of this minimum is related to the radius of the polystyrene particles, while the sharpness of the minimum and the following maximum as well as the existence of further minima and maxima is related to the polydispersity of the particle radius. At high $q$, the scattering is characterized by a $q^{-4}$ dependent decay of the intensity, typical for bulk contrast.

Comparing the curves, a shift of the characteristic minima/ maxima towards higher $q$ values is observed when the SDS concentration used to synthesize the particles is increased. This shift, according to $q \sim 2 \pi / d$, corresponds to a decrease of the size of the PS particles. Furthermore, the systematic blurring out of higher-order minima can be attributed to an increase in polydispersity.

In order to analyze the scattering curves quantitatively, the scattering intensity $I(q)$

$I(q)=n \Delta \rho^{2} V^{2} P(q) S(q)+$ incoherent background

can be modeled using the decoupling approximation [71].

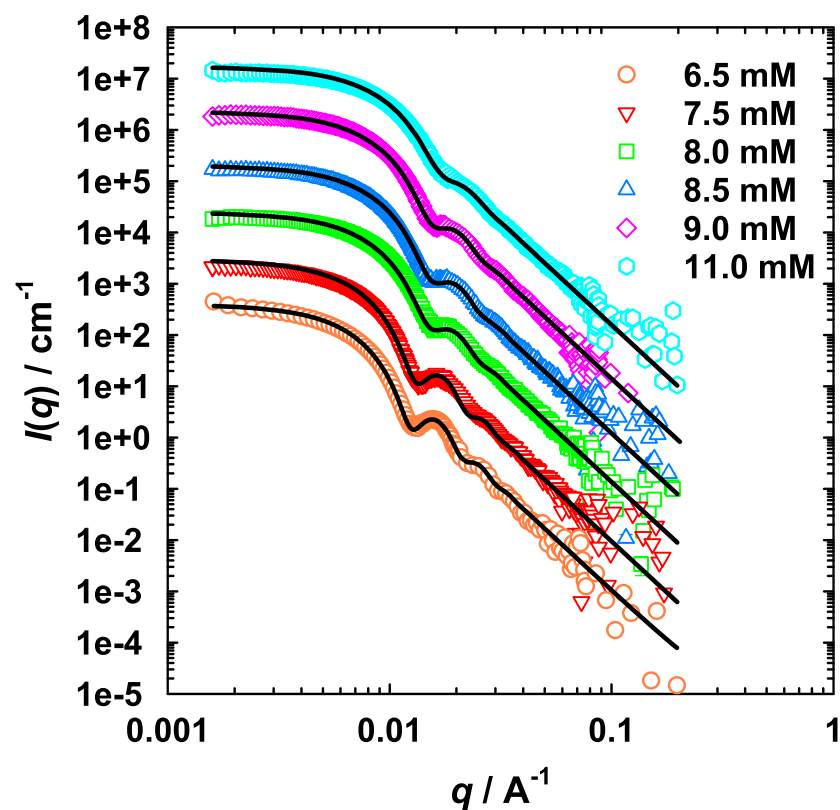

Fig. 1 SANS curves of PS particle dispersions $(\sim 0.1 \mathrm{wt} \%$, obtained via dilution of the aqueous dispersions $(\sim 10 \mathrm{wt} \%)$ with $\left.\mathrm{D}_{2} \mathrm{O}\right)$, synthesized at various SDS concentrations, recorded at $T=25^{\circ} \mathrm{C}$. The scattering profiles were quantitatively described using the form factor of polydisperse spheres [70] (solid curve). Note that the incoherent scattering contribution has been subtracted and that the curves are displaced by a factor of $10^{x}$ with respect to each other

Here, the scattering intensity can be separated into interand intra-particle scattering contributions using the structure factor $S(q)$ and form factor $P(q)$, respectively. $n$ and $V$ are the number density and volume of the particles, and $\Delta \rho^{2}$ is the (squared) difference of the scattering length densities between the particles and the solvent.

Studying very dilute particle dispersions $(\sim 0.1 \mathrm{wt} \%)$, we neglected structure factor contributions and used the form factor of spheres (Eq. 2) [70] convoluted with a Gaussian distribution function to analyze the scattering curves, where $R_{0}$ corresponds to the particle radius and $\sigma$ to its standard deviation. Furthermore, the neutron wavelength spread $\Delta \lambda / \lambda$ was considered. As can be seen in Fig. 1, the experimental scattering data can be quantitatively described using the form factor of polydisperse spheres. From the fits, the particle size and polydispersity $p_{\mathrm{SANS}}=\sigma / R_{0}$ were determined, which are compiled in Table 1 with the results obtained from DLS and SEM.

$$
\begin{aligned}
& P(q, r)=\frac{1}{2}\left(1-\cos 2 q R_{0} e^{-2 \sigma^{2} q^{2}}\right)-q\left(R_{0} \sin 2 q R_{0}+2 q \sigma^{2} \cos 2 q R_{0} e^{-2 \sigma^{2} q^{2}}\right) \\
& +\frac{1}{2} q^{2}\left(-4 q R_{0} \sigma^{2} \sin 2 q R_{0} e^{-2 \sigma^{2} q^{2}}+R_{0}^{2}+\sigma^{2}+R_{0}^{2} \cos 2 q R_{0} e^{-2 \sigma^{2} q^{2}}+\sigma^{2} \cos 2 q R_{0}\left(1-4 \sigma^{2} q^{2}\right) e^{-2 \sigma^{2} q^{2}}\right)
\end{aligned}
$$

All synthesized particles were by default characterized by DLS measurements, which were performed with diluted particle dispersions $(\sim 0.1 \mathrm{wt} \%)$, varying the scattering angle $\theta$ between $30^{\circ}$ and $130^{\circ}$ in steps of $20^{\circ}$ at a temperature of $T=$ 
Table 1 Dependency of the particle radius $R$ and polydispersity $p=\sigma / R$ of polystyrene nanoparticles on the surfactant concentration determined by DLS, SANS and SEM. We estimate the relative uncertainties of $\Delta p_{\mathrm{SANS}}$ and $\Delta p_{\mathrm{SEM}}$ to be $10 \%$

\begin{tabular}{llllll}
\hline$[\mathrm{SDS}] / \mathrm{mM}$ & $<R_{\mathrm{h}}>\mathrm{nm}$ & $R_{0} / \mathrm{nm}$ & $R_{\mathrm{SEM}} / \mathrm{nm}$ & $p_{\text {SANS }}$ & $p_{\text {SEM }}$ \\
\hline 0 & 221 & - & 212 & - & 0.01 \\
1.6 & 170 & - & 165 & - & 0.04 \\
3.3 & 122 & - & 113 & - & 0.02 \\
6.5 & 39 & 36 & 35 & 0.05 & 0.05 \\
7.5 & 35 & 33 & 30 & 0.06 & 0.07 \\
8.0 & 33 & 28 & 30 & 0.09 & 0.07 \\
8.5 & 32 & 27 & 28 & 0.11 & 0.08 \\
9.0 & 32 & 27 & 27 & 0.14 & 0.11 \\
9.8 & 32 & - & 24 & - & 0.13 \\
11.0 & 31 & 24 & 23 & 0.18 & 0.13 \\
13.1 & 31 & - & 22 & - & 0.16 \\
19.6 & 26 & - & 21 & - & 0.13 \\
26.2 & 25 & - & 20 & - & 0.14 \\
\hline
\end{tabular}

$25{ }^{\circ} \mathrm{C}$. The received intensity-time correlation functions were analyzed using CONTIN [66], yielding the hydrodynamic radius $R_{\mathrm{h}}$ and the polydispersity. However, already Provencher realized that for the correct solution of the inversion problem, additional constraints on the solution are needed, which usually rely on prior knowledge about the size distribution itself. Thus, in Table 1, only the hydrodynamic radius $<R_{\mathrm{h}}>$ is given, obtained by averaging over the values obtained for the different $\theta$. Additionally, the radius $R_{\mathrm{SEM}}$ of the PS particles and its polydispersity $p_{\mathrm{SEM}}=\sigma / R_{\mathrm{SEM}}$ were determined via the analysis of the SEM images of the close-packed PS nanoparticle assemblies with ImageJ.

In Fig. 2, left, the values of the particle radius determined by the three methods are plotted as a function of the SDS concentration used in the emulsion polymerization. As expected, at first, the radius decreases strongly with increasing surfactant concentration. This well-known decay can be attributed to a substantial decrease of the water/styrene-interfacial tension which leads to an enhanced stabilization of newly formed primary particles by surfactant molecules. As a result, the growth by coagulation and coalescence of the primary particles is slowed down. Increasing the SDS concentration further, the decrease of the radius weakens considerably, approaching a constant value of the order of $20 \mathrm{~nm}$ at large values of [SDS]. Comparing the values of the particle radius obtained by the different methods, a quantitative agreement is found for SANS and SEM. As expected, the hydrodynamic radii determined by DLS provide somewhat larger values as particles including their hydration shell are detected.

On the right side of Fig. 2, the variation of the polydispersity $p$ with increasing SDS concentration is shown. The polydispersity increases in form of an S-shaped profile from an initially constant value of $p \approx 0.03$ to a plateau value of $p \approx 0.14$ at high values of [SDS]. The point of inflection is located at [SDS] $\approx 8.5 \mathrm{mM}$, i.e., at the concentration where the decrease of the particle radius was found to level off. This increase of polydispersity $p$ with increasing surfactant concentration can be mainly attributed to the appearance of secondary nucleation processes [72]. While at surfactant concentrations below the CMC mainly homogeneous nucleation takes place, above the $\mathrm{CMC}$, a mixed-mode of homogeneous and micellar nucleation mechanism is present, with the latter being predominant. Interestingly, this micellar nucleation mechanism occurred at a considerably lower concentration than expected from the CMC of the binary water-SDS system. Ten years ago, Farías-Cepeda et al. [50] found indications that this mixed mode appears at the critical micelle concentration of the respective polymerizable emulsion systems instead of the corresponding water-surfactant system. Measuring the interfacial tension between water and ethylbenzene in the presence of $\mathrm{K}_{2} \mathrm{SO}_{4}$ as a function of the SDS concentration at the polymerization temperature of $70{ }^{\circ} \mathrm{C}$, they could correlate the polydispersity increase of the synthesized styrene particles with the beginning of micellization, which was found at a considerable lower concentration compared to the CMC of the binary water-SDS-mixture. Note that they used ethylbenzene as a non-polymerizable substituent for styrene while $\mathrm{K}_{2} \mathrm{SO}_{4}$ was added to mimic the initiator potassium peroxodisulfate and to avoid a polymerization during the interfacial tension measurements at $70^{\circ} \mathrm{C}$.

In order to prove that indeed the shape of both the $R([\mathrm{SDS}])$-curve as well as $p([\mathrm{SDS}])$-curve is correlated with the micellization, we determined the CMC of the emulsion polymerization system water-styrene-SDS. Due to the low initiator concentration $(\sim 0.004 \mathrm{mM})$ compared to FaríasCepeda et al. [50] $(\sim 10 \mathrm{mM})$, the influence of the salt was neglected. The interfacial tension between aqueous SDS solutions and styrene was measured as a function of the SDS concentration at $25^{\circ} \mathrm{C}, 30^{\circ} \mathrm{C}, 45^{\circ} \mathrm{C}$, and $60^{\circ} \mathrm{C}$ using the spinning drop technique. The recorded interfacial tension profiles were analyzed quantitatively with the LangmuirSzyszkowski [73, 74] model, shown in the Supplementary Information Fig. S1. The obtained values of the CMC and the interfacial tensions $\gamma_{\mathrm{CMC}}$, the surface excess $\Gamma_{\mathrm{CMC}}$ at the $\mathrm{CMC}$, and the surfactant head group area $a_{\mathrm{CMC}}$ at the respective CMCs are summarized in Table S1.

In Fig. 3, the temperature dependence of the CMC in the water-styrene-SDS system is shown by plotting $\ln (\mathrm{CMC})$ as a function of temperature. The comparison with the temperature dependence of the CMC in the binary water-SDS system [52] clearly shows that the presence of a styrene reduces the CMC due to the stronger tendency of the SDS molecules to adsorb at the water/styrene than at the water-air interface. However, the trend of the CMC with temperature is similar in both the binary and the ternary system. In order to determine the $\mathrm{CMC}$ at the polymerization temperature of $80{ }^{\circ} \mathrm{C}$ (which was experimentally not accessible), we used a 


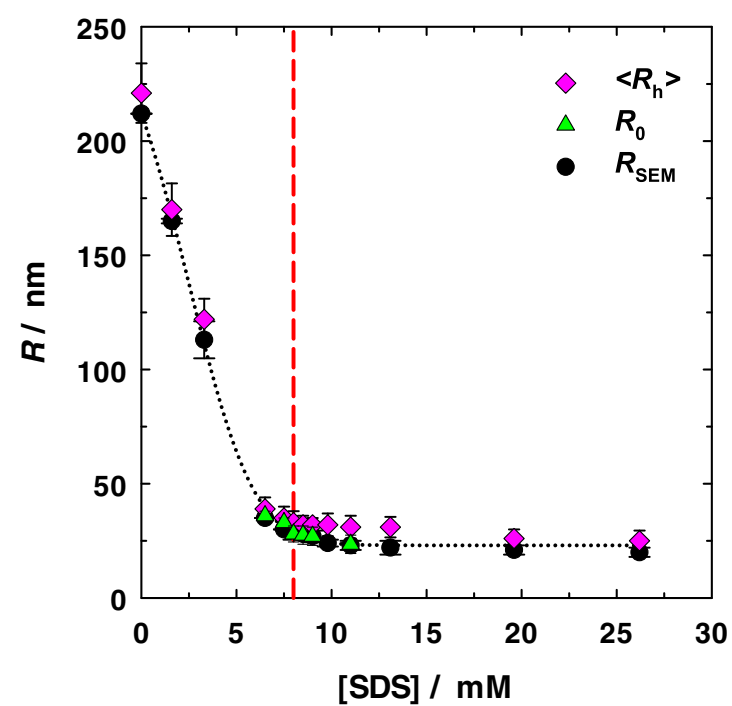

Fig. 2 Left. Particle radius $R$ of polystyrene particles synthesized by emulsion polymerization at various SDS concentrations determined by DLS, SANS, and SEM. As the SDS concentration increases, the radius of the particles decreases and approaches an almost constant value above the CMC of the ternary water-styrene-SDS at $T=80^{\circ} \mathrm{C}$ (dashed red line).

second-degree polynomial to describe the temperature dependence of the CMC [75]. According to that, we obtained a $\mathrm{CMC}=8.0 \pm 0.5 \mathrm{mM}$ for the ternary water-styrene-SDS system at $T=80^{\circ} \mathrm{C}$, whereas the CMC for the binary water-SDS system is specified with $13.1 \mathrm{mM}$ [52].

In Fig. 2, the determined CMC of water-styrene-SDS is represented as a dashed red line. As one can see, it coincides almost quantitatively with the concentration at which the

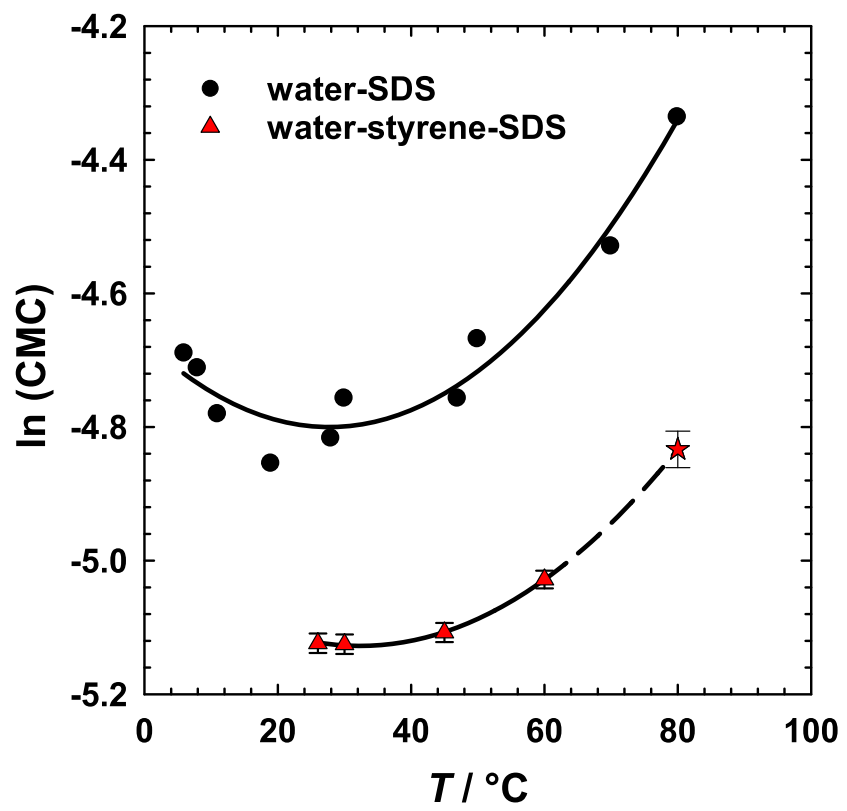

Fig. $3 \ln (\mathrm{CMC})$ as a function of the temperature for the ternary waterstyrene-SDS system and the binary water-SDS system [52] for comparison. Note that the presence of styrene considerably reduces the $\mathrm{CMC}$ of the binary water-SDS system

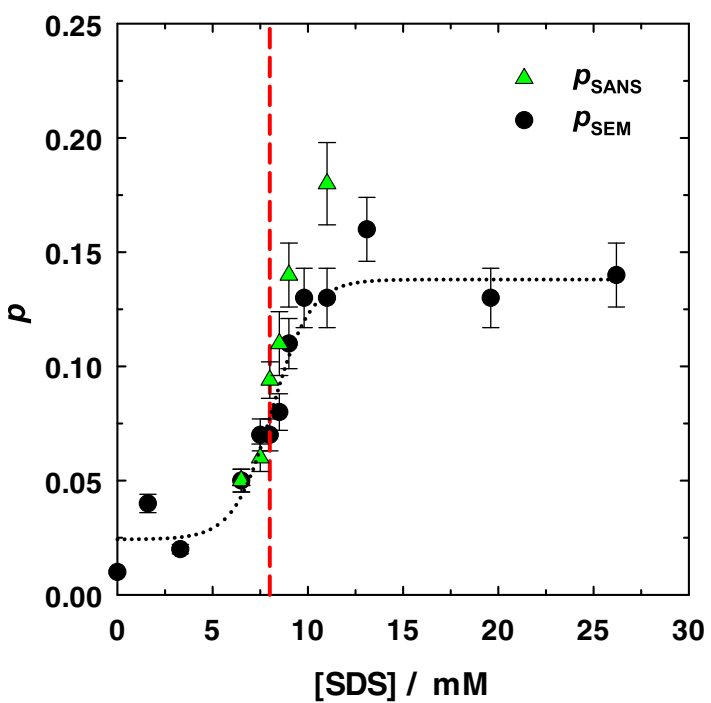

Right. Polydispersity $p_{\text {SANS }}$ and $p_{\text {SEM }}$ of the particles obtained from SANS and SEM images, respectively. Closely to the CMC, the polydispersity starts to increase due to competing nucleation and growth mechanisms

radius of the polystyrene nanoparticles approaches a constant value and with the inflection point of the polydispersity profile. Thus, these results confirm that the CMC of the ternary system determines where additional micellar nucleation mechanisms contribute to the particle formation and thus lead to a considerable increase of the polydispersity of the synthesized nanoparticles.

Drying of the PS nanoparticle dispersions leads to the formation of close-packed PS nanoparticle assemblies, which are later on used for the preparation of porous polymers and $\mathrm{ZnO}$ inverse opals. The ordering of the close-packed assemblies of the PS particles was studied by SEM and SAXS. The recorded SEM images are shown in Fig. 4 together with the particle size distributions (insets). They clearly indicate that the polydispersity of the PS nanoparticles has a high impact on the assembly of the particles. Taking a closer look at assemblies of particles synthesized at $[\mathrm{SDS}] \leq 8.5 \mathrm{mM}$, a hexagonal layer arrangement is found. Studying these close-packed assemblies at different magnifications, different types of packing defects such as vacancies, stacking faults as well as cracks were found (see Fig. S2). Drying of somewhat more polydisperse particles synthesized at [SDS] $>8.5 \mathrm{mM}$, leads to particle assembly without hexagonal layer ordering. However, these less ordered assemblies are more closely packed which results in a considerable increase in packing efficiency due to the filling of some of the voids with the appropriate particles.

To quantify the loss of the packing order, the structure of the close-packed assemblies of PS nanoparticles synthesized at $[\mathrm{SDS}]=6.5 \mathrm{mM}, 7.5 \mathrm{mM}, 8.0 \mathrm{mM}, 8.5 \mathrm{mM}, 9.0 \mathrm{mM}$, and $11.0 \mathrm{mM}$ was investigated by SAXS experiments at $T=$ $25^{\circ} \mathrm{C}$. The scattering curves are shown in Fig. 5 in a double 

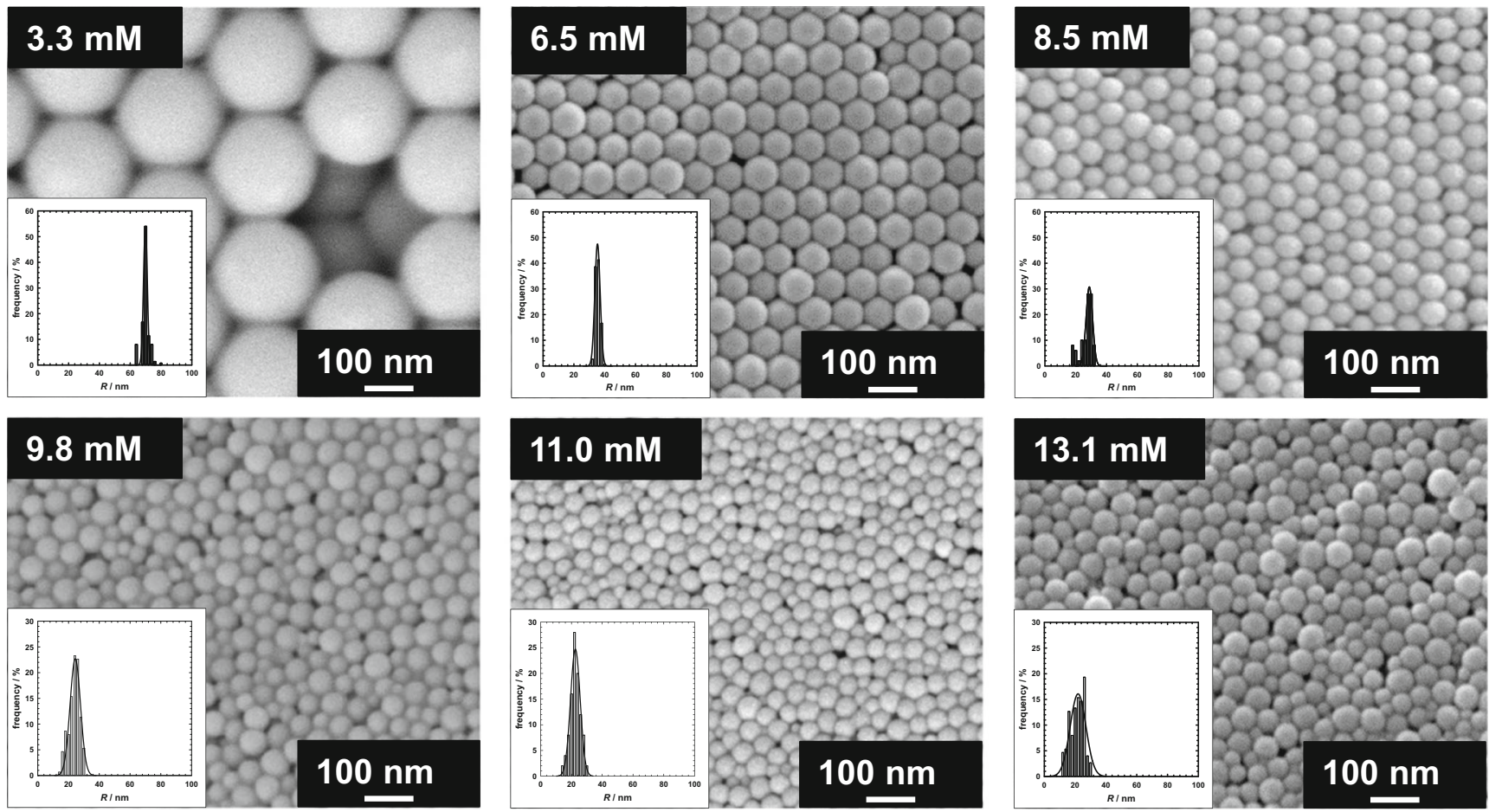

Fig. 4 Top view SEM images of close-packed PS nanoparticles as well as particle size distribution (inset), synthesized at various [SDS] and at $T=$ $80{ }^{\circ} \mathrm{C}$. Increasing [SDS] to $>8.5 \mathrm{mM}$ the ordering of the particle

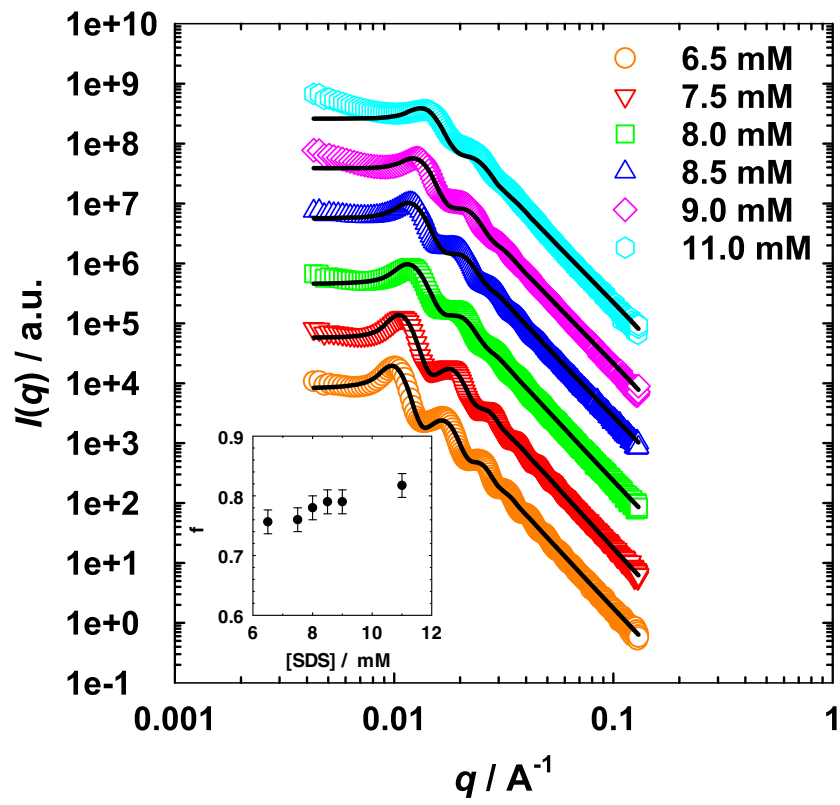

Fig. 5 SAXS curves of close-packed PS particles obtained via drying of aqueous dispersions, synthesized at different SDS concentrations. The loss in the packing order correlates to the increase in particle polydispersity at the $\mathrm{CMC}=8.0 \pm 0.5 \mathrm{mM}$ of water-styrene-SDS. The scattering data could be almost quantitatively described using the local monodisperse approximation [76] including the form factor of polydisperse spheres and the structure factor of sticky hard spheres [57-59] (solid lines). Note that the incoherent scattering contribution has been subtracted and that the curves are displaced by a factor of $10^{\mathrm{x}}$ with respect to each other. The inset represents the determined particle volume fraction which increases with increasing [SDS] with an estimated error to be $\Delta \Phi= \pm$ 0.02 assemblies decreases considerably due to an increase of the particle polydispersity. At the same time, the size of the PS nanoparticles is decreasing

logarithmic representation of the coherent scattering intensity and the scattering vector $q$. For each curve, a slight increase of the scattering intensity towards low $q$ is observed which can be attributed to the scattering of larger defects as well as the micrometer-sized granular structure of the sample. With increasing $q$, a pronounced first interaction peak occurs, with $q_{\max }=2 \pi / d$ being related to the nearest neighbor distance. Towards larger $q$, further maxima and minima of the scattering intensity are detected. Thereby, the scattering intensity decays with $q^{-4}$. Comparing the scattering curves of the close-packed assemblies of PS nanoparticles, it is obvious that the positions of the maxima/minima shift to larger $q$ values with increasing concentration of SDS used in the synthesis. This trend proves that the distance between the particles decreases when the particle size is decreased, as expected. Furthermore, the systematic blurring out of higher-order maxima and minima can be attributed to an increase in polydispersity of particle distances which are a consequence of the increasing particle polydispersity.

In comparison to the scattering profiles of dilute particle dispersions shown in Fig. 1, additional scattering contributions arise from interparticle interactions, which means that the structure factor $S(q)$ must be taken into account to model the scattering curves of the close-packed assemblies of PS nanoparticles. Herein, we used the local monodisperse approximation [76] (Eq. 4) instead of the decoupling approximation to combine the form factor with the structure factor, since it has been shown that it provides a more reasonable 
description of interference effects, especially in systems consisting of particles with high polydispersities at high volume fraction

$I(q)=n \Delta \rho^{2} \int N(r) V(r)^{2} F(q, r)^{2} S\left(q, R_{i}(r)\right) d r$

Here, $N(r)$ is the particle size distribution function, $V(r)$ the volume of a particle with the radius $r$, and $F(q, r)$ is the scattering amplitude of spheres. The structure factor $S\left(q, R_{\mathrm{i}}(\mathrm{r})\right)$ accounts for the interaction of particles of the same size using the model of sticky hard spheres [77-79]

$S(x)=\frac{1}{A(x)^{2}+B(x)^{2}}$

in which the parameters $A(\mathrm{x})$ and $B(\mathrm{x})$ are given by

$A(x)=1+12 \cdot \eta \cdot\left[\alpha \frac{\sin x-x \cdot \cos x}{x^{3}}+\beta \frac{1-\cos x}{x^{2}}-\frac{\tilde{\lambda}}{12} \cdot \frac{\sin x}{x}\right]$

and

$B(x)=12 \cdot \eta \cdot\left[\alpha \frac{\frac{x^{2}}{2}-x \sin x+1-\cos x}{x^{3}}+\beta \frac{x-\sin x}{x^{2}}-\frac{\tilde{\lambda}}{12} \cdot \frac{1-\cos x}{x}\right]$,

where $x=q \cdot\left(2 R_{0}+\Delta\right)$ is proportional to the interaction diameter given by the particle radius $R_{0}$ obtained from the analysis of the SANS measurements (see Table 1) and the thickness $\Delta$ of the attractive square well potential of depth $-\varepsilon_{\mathrm{S}}$. Thus, the stickiness parameter $\tau$ can be calculated by.

$\frac{1}{\tau}=\frac{12 \cdot \Delta}{\left(2 R_{0}+\Delta\right)} \cdot e^{\frac{\varepsilon_{S}}{k_{B} T}}$

The parameter $\eta$ is related to the volume fraction $\phi$ by

$\eta=\phi\left(\frac{2 R_{0}+\Delta}{2 R_{0}}\right)^{3}$

as well as

$\mu=\widetilde{\lambda} \eta(1-\eta), \alpha=\frac{1+2 \eta-\mu}{(1-\eta)^{2}}, \beta=\frac{-3 \eta+\mu}{2(1-\eta)^{2}}$

where $\tilde{\lambda}$ is defined by

$\widetilde{\lambda}=\operatorname{Min}\left\{6\left[\frac{\tau}{\eta}+\frac{1}{1-\eta}\right] \pm 6 \cdot \sqrt{\frac{\tau}{\eta}+\frac{1}{1-\eta}}\right\}$.

As can be seen in Fig. 5, the local monodisperse approximation allows to describe the scattering curves almost quantitatively. Small but systematic deviations between the approximation and the SAXS data can be observed at low $q$, which are related to the scattering of larger defects as well as the micrometer-sized granular structure of the sample. Furthermore, by specifying the position of interaction peaks, the first minimum of the approximation appears at slightly larger $q$-values than found in the experimental data. This weakness of the local monodisperse approximation arises from the neglection of the interparticle interactions between particles of different sizes [76, 80]. Furthermore, one might note that the structure factor (sticky hard sphere) of each particle species of radius $R$ is based on the Percus-Yevick approximation, resulting in an out-of-phase shift as already discussed elsewhere [81, 82].

Note that for the analysis, the radius $R_{0}$ determined by the SANS experiments (Table 1) was used, while the polydispersity had to be slightly increased, especially for the closepacked particle assemblies synthesized at low SDS concentrations ([SDS] $<9.0 \mathrm{mM}$ ) in order to account for the fact that the packing is not crystal-like. The obtained values of the polydispersity $p_{\mathrm{SAXS}}$, the square well thickness $\Delta$, the depth $-\varepsilon_{\mathrm{S}}$ of the potential and the particle volume fraction $\phi$ are compiled in Table 2. The trend of the volume fraction $\phi$ of particles in the close-packed assemblies with the SDS concentration is represented in the inset of Fig. 5. As can be seen, the particle volume fraction increases systematically from $\phi=0.76$ at $[\mathrm{SDS}]=6.5 \mathrm{mM}$ towards $\phi=0.82$ at $[\mathrm{SDS}]=11.0 \mathrm{mM}$. Impressively, the analysis of the SAXS curves confirms the observations made in the SEM pictures, i.e., that the polydisperse distributions of particles synthesized at [SDS] $>$ CMC allow for a closer packing. Filling some of the voids with the appropriate particles enables high packing efficiencies, i.e., particle volume fraction larger than that of the hexagonal close-packing for monodisperse spherical particles $(\phi=0.74)$.

In summary, in this part, we have demonstrated the tuneability of the PS particle size $\left(R_{\mathrm{SEM}} \approx 210-20 \mathrm{~nm}\right)$ as well as the polydispersity $\left(p_{\text {SEM }} \approx 0.01-0.14\right)$ by systematic variation of the surfactant concentration applied in the emulsion polymerization. The increased polydispersity was found

Table 2 Results of the analysis of the SAXS curves using the local monodisperse approximation [76], the sticky hard sphere structure factor $[77,79]$, and the radius $R_{0}$ determined by the SANS: polydispersity $\left(p_{\mathrm{SAXS}}=\sigma / R\right)$, thickness of the square well $\Delta$, stickiness parameter $\tau$, depth of the square well potential $-\varepsilon_{\mathbf{S}}$ and the volume fraction $\phi$ of assembled polystyrene nanoparticles

\begin{tabular}{llllll}
\hline$[\mathrm{SDS}] / \mathrm{mM}$ & $p_{\text {SAXS }}$ & $\Delta / \mathrm{nm}$ & $\tau$ & $-\varepsilon_{\mathbf{S}} / \mathrm{kT}$ & $\phi$ \\
\hline 6.5 & 0.10 & 28 & 0.45 & 1.6 & 0.76 \\
7.5 & 0.12 & 29 & 0.47 & 1.4 & 0.76 \\
8.0 & 0.15 & 30 & 0.49 & 1.2 & 0.78 \\
8.5 & 0.15 & 37 & 0.50 & 1.0 & 0.79 \\
9.0 & 0.14 & 38 & 0.51 & 0.9 & 0.79 \\
11.0 & 0.16 & 38 & 0.52 & 0.8 & 0.82 \\
\hline
\end{tabular}


to induce a loss of the packing order in close-packed PS nanoparticles, while the particle volume fraction forming the assembly increases.

\section{From close-packed PS nanoparticles to mesoporous PS using the NF-CID principle and its two-step optimization}

In the following, the adjustable close-packed PS nanoparticle assemblies prepared and characterized in the first part of this work are used to form porous polymers applying the continuity inversion of dispersion (NF-CID) principle $[25,26]$ and its new two-step optimization. Some years ago, the feasibility of the NF-CID principle was proven by means of PMMA nanoparticles [25]. In this systematic study, Müller investigated the influence of the NF-CID process parameters, e.g., particle radius, temperature, pressure, and $\mathrm{CO}_{2}$ exposure time, on the pore size and morphology of the obtained porous polymer. Grassberger [29] and some of us [37] applied the NF-CID principle to close-packed PS nanoparticle assemblies. In these studies, it was found that most of the prepared porous polymers exhibit a close-pore morphology. Furthermore, the findings clearly show that both increasing temperature and $\mathrm{CO}_{2}$ exposure time lead to a coarsening of the structure due to Ostwald ripening $[83,84]$ as well as coagulation and coalescence $[85,86]$. Now that we are able to synthesize PS particles with an adjustable radius and polydispersity, we studied the impact of the particle size on the NF-CID principle. The results are summarized in the Supporting Information (Fig. S3). They show that the foaming of hexagonal assemblies of monodisperse PS nanoparticles $\left(R_{\mathrm{SEM}}=35 \mathrm{~nm}, p_{\mathrm{SEM}}=\right.$ $0.05)$ filled with sc- $\mathrm{CO}_{2}$ results in an inhomogeneous porous structure with large pores $\left(R_{\text {pore }}=4.2 \pm 1.4 \mu \mathrm{m}\right)$ most likely originating from the foaming of packing defects. Instead, foaming a close-packed assembly of polydisperse smaller PS particles $\left(R_{\mathrm{SEM}}=20 \mathrm{~nm}, p_{\mathrm{SEM}}=0.13\right)$ a homogeneous structure with significantly smaller pores $\left(R_{\text {Pore }}=450 \pm 100 \mathrm{~nm}\right)$ was found to be related to the use of smaller particles, but mainly to the smaller number of packing defects due to the higher packing efficiency $(\phi \approx 0.82)$.

However, the NF-CID procedure still suffers from the coarsening of the structure during both the inversion and expansion step. On the one hand, a temperature above the reduced glass temperature $T_{\mathrm{g}}{ }^{*}$ of the $\mathrm{CO}_{2}$ saturated polystyrene is essential to ensure the inversion of the close-packed particle assemblies to sc- $\mathrm{CO}_{2}$ nanodroplets in a highly viscous polymer matrix but also induces the coarsening of these droplets. On the other hand, adjusting a temperature too close to $T_{\mathrm{g}}{ }^{*}$ might inhibit the foaming of the sample, which quickly returns to the glassy state during the subsequent expansion. To overcome these issues, we optimized the NF-CID principle as illustrated in Fig. 6 by conducting the inversion and expansion step at different temperatures. Therefore, the close-packed assembly of polymer nanoparticles is saturated with the supercritical blowing agent at a pressure $p>p_{\mathrm{c}}$ (above the critical pressure of the blowing agent $\left(\mathrm{CO}_{2}\right)$ ) and a temperature above but close to $T_{\mathrm{g}} *$ ensuring the inversion of the close-packed particle assembly to blowing agent nanodroplets in a highly viscous polymer matrix (a). To limit coarsening processes during the expansion, the temperature is decreased to $T=$ $25{ }^{\circ} \mathrm{C}$, i.e., below $T_{\mathrm{g}}{ }^{*}$, to fix the blowing agent droplets by freezing the polymer matrix (b). Then, the pressure is carefully and slowly released to avoid the bursting of the solid matrix (c). Making use of the remaining blowing agent dissolved in the polymer matrix, a subsequent heating step transfers this porous polymer to an open-cellular mesoporous polymer via gentle foaming $(\mathrm{d})$.

The feasibility of this optimized NF-CID principle was studied using a close-packed assembly of PS nanoparticles with $R_{\mathrm{SEM}}=23 \mathrm{~nm}$ and $p_{\mathrm{SEM}}=0.13 . \mathrm{CO}_{2}$ was added as blowing agent adjusting a pressure of $p=250$ bar and a temperature of $T=65{ }^{\circ} \mathrm{C}$ for $30 \mathrm{~min}$. This exposure time on the one hand ensured the inversion of the close-packed particle assembly to sc- $\mathrm{CO}_{2}$ nanodroplets to blowing agent-filled inclusions in a highly viscous polymer matrix but on the other hand also limited the coarsening of the inclusions. Further coarsening processes are then avoided by cooling the sample down to $T=$ $25^{\circ} \mathrm{C}$, while keeping the pressure at $p=250$ bar. At this temperature, the $\mathrm{CO}_{2}$ nanodroplets are fixed in a glassy polystyrene matrix. Afterwards, the pressure is released at $T=25^{\circ} \mathrm{C}$ in order to avoid coarsening processes, which were observed when the expansion was performed at temperatures above $T_{\mathrm{g}}{ }^{*}$. Note that the pressure was released very slowly $(\sim 10 \mathrm{~min})$ to prevent the glassy matrix from bursting. Being in the glassy state, both the polymer matrix and the $\mathrm{CO}_{2}$ nanodroplets do not expand during this process. Subsequently, the temperature is increased back to $T=65^{\circ} \mathrm{C}$ for $10 \mathrm{~min}$ to soften the glassy matrix. Making use of the remaining blowing agent dissolved in the polymer matrix and the lower $\mathrm{CO}_{2}$-solubility at high temperatures, this heating step leads to a gentle foaming of the porous polymer. The structure of the obtained porous polymer is then studied by SEM, providing the pictures shown in Fig. 7. The lower magnification picture (Fig. 7, left) shows a clearly bimodal structure consisting of large almost spherical pores which are surrounded by extended regions exhibiting mesopores of $R_{\text {pore }} \approx 25 \mathrm{~nm}$ and open-cellular morphology (Fig. 7, right). The fact that the radius of the mesopores almost quantitatively equals the radius of the used PS particles, i.e., $R_{\text {pore }} \approx R_{\mathrm{SEM}}$, shows that coarsening processes could be greatly reduced when the expansion step is performed after the $\mathrm{CO}_{2}$-filled inclusions are fixed in a glassy polystyrene matrix.

To conclude, open-cellular mesoporous polymers containing some large pores can be easily prepared using the suggested optimization of the NF-CID principle. Assuming that the large pores most probably originate from defects in the close-packed PS nanoparticle 
Fig. 6 Schematic representation of the modified NF-CID method. As for the conventional NF-CID, the close-packed assembly of polymer nanoparticles is soaked with a supercritical blowing agent adjusting the temperature to $T>T_{\mathrm{g}}$ * to enable the continuity inversion into blowing agent filled droplets in a highly viscous polymer matrix (a). After that, the system is cooled to $T<T_{\mathrm{g}}{ }^{*}$ keeping the pressure constant at $p>p_{c}$ to fix the droplets in the glassy matrix (b). Then, the pressure is very slowly released at a constant temperature to avoid the bursting of the matrix (c). A subsequent heating step transfers this porous polymer to an opencellular mesoporous polymer (d) via gentle foaming a)

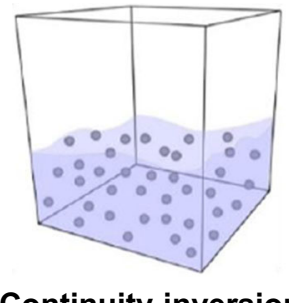

Continuity-inversion

- sc-fluid inclusion

polymer matrix

d)

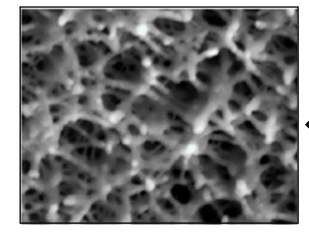

Rapid heating

Open-cellular mesoporous polymer b)

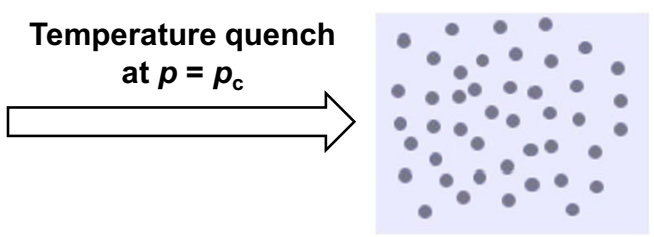

Freezing of polymer matrix $T<T_{\mathrm{g}}{ }^{*}, p>p_{\mathrm{c}}$

c)

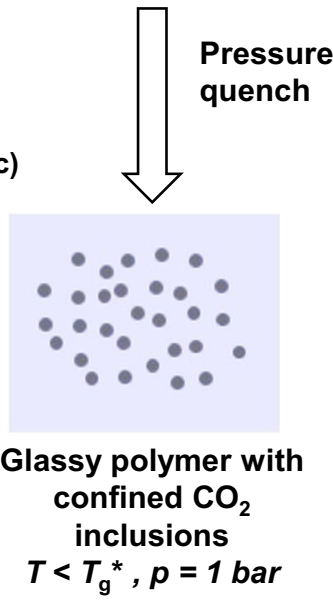

assemblies, the number density of large pores might be adjustable via tuning the polydispersity of the polystyrene particles. Note that inhomogeneous foams which consist of two kinds of cells with a significant difference in cell size attract more and more attention compared with uniform cell structure as they were found to exhibit superior sound absorption capacities [87], heat insulation [88], and mechanical properties [89].

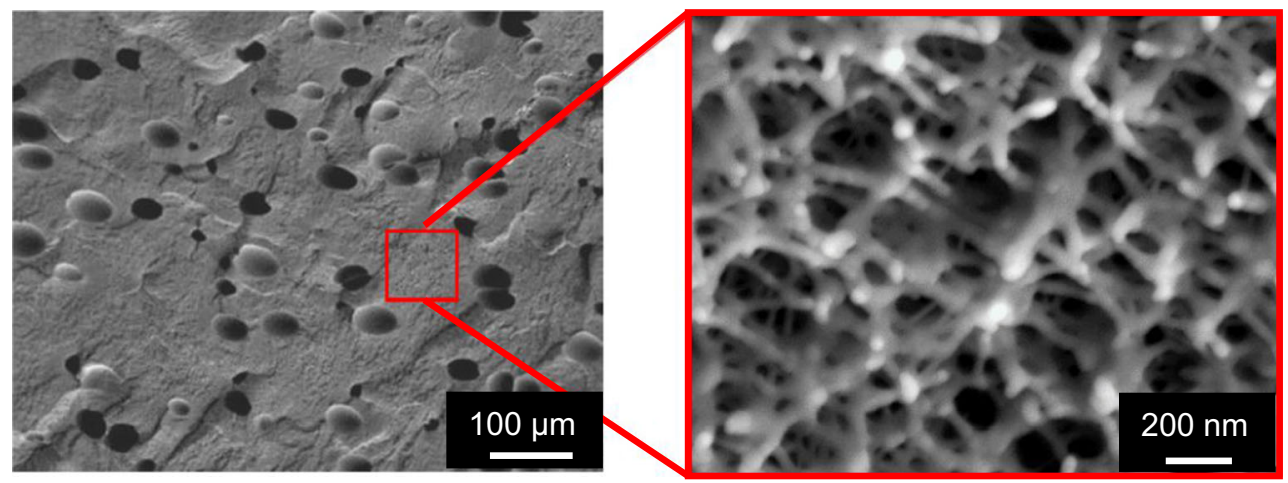

Fig. 7 SEM-images of the porous polystyrene obtained using the modified NF-CID method. A continuity-inversion of a close-packed PS nanoparticle assembly $\left(R_{\mathrm{SEM}}=23 \pm 3 \mathrm{~nm}\right.$ and a moderate polydispersity of $p_{\mathrm{SEM}}=0.13$ ) is induced due to a $30 \mathrm{~min}$ exposure to $\mathrm{CO}_{2}$ at $T=65^{\circ} \mathrm{C}$, $p=250$ bar. After cooling the system down to $T=25^{\circ} \mathrm{C}$ while keeping the pressure at $p=250$ bar, the pressure was slowly released. Gentle foaming was subsequently induced by increasing the temperature to $T=65{ }^{\circ} \mathrm{C}$ for $10 \mathrm{~min}$. (left) Low magnification SEM image showing the presence of large pores $(15 \mu \mathrm{m})$. (right) Higher magnification SEM image proving the mesoporous open-cellular structure $\left(R_{\text {pore }} \approx 25 \mathrm{~nm}\right)$ of the surrounding regions 

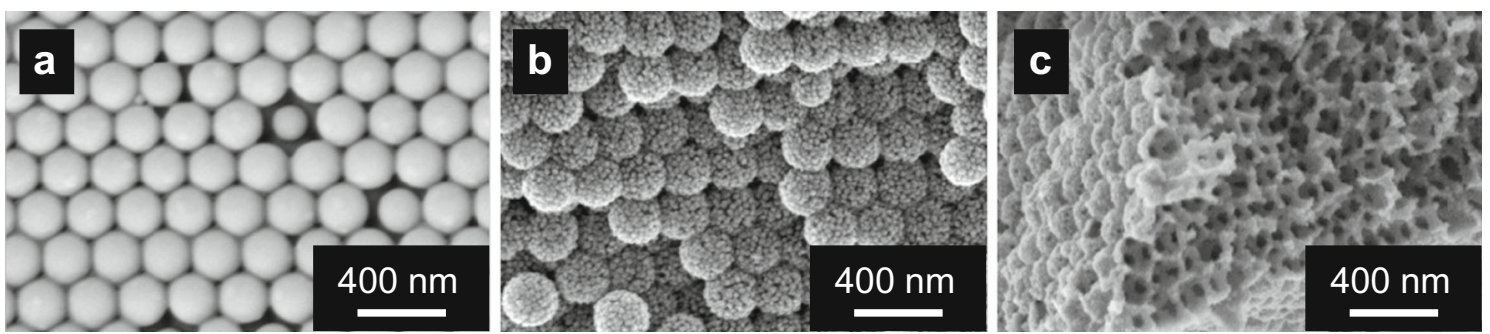

Fig. 8 SEM images of a) close-packed assemblies of monodisperse PS particles with a radius of $R_{\mathrm{SEM}}=113 \mathrm{~nm}$ and $p_{\mathrm{SEM}}=0.02$, b) close-packed assembly of monodisperse PS particles mineralized with $\mathrm{ZnO}$ after 5 deposition cycles, and c) $\mathrm{ZnO}$ inverse replica obtained after the annealing of b)

\section{From close-packed PS nanoparticles to $\mathrm{ZnO}$ inverse opals}

In a second application, the close-packed PS nanoparticle assemblies were used as a template for the synthesis of inverse opals. $\mathrm{ZnO}$ inverse opals were prepared in three steps. First, PS nanoparticles with a radius of $R_{\mathrm{SEM}}=113 \mathrm{~nm}$ and $p_{\mathrm{SEM}}=0.02$ were assembled in a close-packed structure, as can be seen in Fig. 8a. They showed a common for the opal structures pearlescent reflection color. In a second step, the PS structured template was infiltrated with $\mathrm{ZnO}$ precursor solution, which was subsequently mineralized via the chemical bath deposition (CBD) method [63]. For a successful deposition of $\mathrm{ZnO}$ within the voids of the template, a charged template surface is required. Although polystyrene is relatively hydrophobic, after 5 deposition cycles, the surface of the PS particles was uniformly covered with $\mathrm{ZnO}$ nanoparticles with a radius of approximately 13 $\pm 2 \mathrm{~nm}$ (Fig. 8b). A similar observation was made when porous PS polymers obtained by the NF-CID method were mineralized applying the same procedure [37]. In this case, the oxide deposition was attributed to the presence of charged SDS residues on the surface of the PS particles. While the hydrophobic dodecyl chains of the SDS molecules are assumed to be embedded in the polymer particles during the polymerization process, their hydrophilic and negatively charged sulfate $\left(\mathrm{SO}_{4}{ }^{-}\right)$head groups stay most probably fixed at the PS particle surface enabling the $\mathrm{ZnO}$ deposition [37].

The size of the $\mathrm{ZnO}$ nanoparticles is controlled by the presence of PVP in the deposition solution, which serves as a structure-directing agent and restricts the particle growth [90]. Additionally, the presence of small amounts of water in the precursor solution accelerates the thermohydrolysis, slightly increasing the particle size and allowing particle size adjustment [91]. Therefore, to achieve a faster filling of the voids in the close-packed PS nanoparticle assembly and to reduce the number of the deposition cycles, 2 vol.\% water was added to the $\mathrm{ZnO}$ deposition solution. As opposed to the homogeneous and dense thin films deposited on various organic templates applying this mineralization procedure [63, 92], the close-packed PS particles were covered with a loose film of $\mathrm{ZnO}$ particles. One might speculate that this different behavior must be related to the surface properties, i.e., the curvature and nature of the template surface. In spite of the formation of a loose film of $\mathrm{ZnO}$ particles on the template particle's surface after 5 deposition cycles, annealing of the $\mathrm{PS} / \mathrm{ZnO}$ hybrid resulted in the third step in the formation of an ordered inverse replica of the close-packed PS nanoparticle assembly. As can be seen in Fig. 8c, the $\mathrm{ZnO}$ inverse opal structure consists of spherical pores with a radius of around $74 \pm 7 \mathrm{~nm}$. Compared to the diameter of the PS template particles, the pore size in the $\mathrm{ZnO}$ inverse opal is significantly reduced due to a structure shrinkage during the calcination process. Moreover, the porous structure has open porosity owing to the presence of interconnecting circular pores.

To conclude this part, a close-packed bulk sample of monodisperse PS nanoparticles with a radius of $R_{\mathrm{SEM}}=113 \mathrm{~nm}$ was successfully used to prepare a $\mathrm{ZnO}$ inverse opal with open porosity. The influence of different parameters on the pore size and morphology of the porous material is currently under investigation.

\section{Conclusion}

Mesoporous materials are potential candidates for a wide range of applications such as catalysis, sorption, and sensing. In this study, we systematically investigated the influence of the sodium dodecyl sulfate (SDS) concentration utilized in the emulsion polymerization on both the properties of the obtained polystyrene (PS) nanoparticles and the morphology of the close-packed assemblies formed by these particles. Subsequently, these templates were used for the preparation of novel mesoporous polystyrene and $\mathrm{ZnO}$ inverse opals.

In the first part, the radius and polydispersity of PS nanoparticles synthesized at different SDS concentrations were determined by small-angle neutron scattering (SANS) and dynamic light scattering (DLS). From the quantitative analysis of the data, the expected strong decrease of the particle radius was found with increasing SDS concentration which levels off at $[\mathrm{SDS}] \approx 8.5 \mathrm{mM}$. The point of inflection of the S-shaped polydispersity profile, which increases from $p \approx 0.03$ to $p \approx$ 0.14 , was determined at the same concentration. Both observations are well-known and can be explained by additional micellar nucleation contributing to the particle formation 
when the critical micelle concentration (CMC) is approached. Interestingly, the micellar nucleation occurred at a considerably lower concentration than expected from the CMC of the binary water-SDS system. Accordingly, the CMC of the system at hand, i.e., the ternary system water-styrene-SDS, was determined by temperature-dependent measurements of the water/styrene-interfacial tension using the spinning drop technique. Extrapolating the found trend to the polymerization temperature of $80^{\circ} \mathrm{C}$, the $\mathrm{CMC}=8.0 \pm 0.5 \mathrm{mM}$ was shown to agree almost quantitatively with the concentration at which the decrease of PS nanoparticle radius levels off and where the polydispersity profile exhibits its inflection point.

Drying of the dispersions of PS nanoparticles led to the formation of close-packed PS nanoparticle assemblies characterized by scanning electron microscopy (SEM) and smallangle X-ray scattering (SAXS). Both techniques show that the increase in particle polydispersity induces a loss in the packing order. Interestingly, the quantitative analysis of the SAXS curves using the local monodisperse approximation [76] and the sticky hard sphere structure factor [77, 79] confirmed the observations made in the SEM pictures, i.e., that the polydisperse distributions of particles synthesized at [SDS] $>\mathrm{CMC}$ allow for a closer packing. Filling some of the voids with the appropriate particles was found to enable high packing efficiencies, i.e., particle volume fractions up to 0.82 , which are considerably larger than that of the close-packing of monodisperse spheres (0.74). This denser packing might be advantageous for the application of the obtained porous structures as a substrate for catalytically active compounds or metal nanoparticles.

In the second part, the adjustable close-packed PS nanoparticle assemblies prepared and characterized in the first part were used to form mesoporous polystyrene and $\mathrm{ZnO}$ inverse opals. Applying the two-step optimization of the continuity inversion of dispersion (NF-CID) principle [25, 26], we were able to prepare a highly porous polystyrene with a bimodal structure consisting of $15-\mu \mathrm{m}$-sized almost spherical pores which are surrounded by extended regions of interconnected mesopores of $R_{\text {pore }} \approx 25 \mathrm{~nm}$. Coarsening processes occurring in the original NF-CID principle could be greatly reduced when the expansion step was performed after the $\mathrm{CO}_{2}$ nanodroplets were fixed in a glassy polystyrene matrix. Through this measure, the radius of the mesopores was found to be an almost one-to-one copy of the used PS particle radius.

In another application, a close-packed bulk sample of monodisperse PS nanoparticles with a radius of $R_{\mathrm{SEM}}=$ $113 \mathrm{~nm}$ was successfully used to prepare a $\mathrm{ZnO}$ inverse opal with open porosity as a proof of concept. Thereby, the voids of this template were mineralized with $\mathrm{ZnO}$ via the chemical bath deposition (CBD) method [63]. After 5 deposition cycles, the surface of the PS particles was found to be uniformly covered with ZnO-nanoparticles. Even more interestingly, despite the loose film of $\mathrm{ZnO}$ particles covering the PS nanoparticle surface, annealing of the $\mathrm{PS} / \mathrm{ZnO}$ hybrid resulted in the formation of an ordered inverse replica of the close-packed PS nanoparticle assembly with a pore radius of around $74 \pm 7 \mathrm{~nm}$.

Supplementary Information The online version contains supplementary material available at https://doi.org/10.1007/s00396-020-04791-5 .

Acknowledgments The authors would like to thank D. Zauser, S.-Y. Tseng, and K. Schneider for performing SANS measurements at the Institute Laue Langevin (ILL) and the Heinz-Maier-Leibnitz Zentrum (MLZ). Furthermore, we would like to acknowledge the ILL and the MLZ, in providing facilities for the SANS measurements and the valuable support of the local contacts R. Schweins and H. Frielinghaus. For the maintenance of the high-pressure cells, the authors thank B.Tschertsche and D. Relovsky, as well as the scientific facility Nanostrukturlabor of J. Weis and the department of G. Richter from the Max Planck Institutes in Stuttgart, Germany, for their technical support and equipment access. Financial support by the Deutsche Forschungsgemeinschaft DFG (grant number $358283783-$ CRC 1333) is gratefully acknowledged. T.H. and C.D. acknowledge funding of the SAXS/WAXS setup by the DFG (Grant INST 215/432-1 FUGG).

Funding Open Access funding enabled and organized by Projekt DEAL. Funded by the Deutsche Forschungsgemeinschaft (DFG, German Research Foundation) - Project number 358283783 - SFB 1333 subprojects $\mathrm{A} 7$ and $\mathrm{A} 5$.

\section{Compliance with ethical standards}

Conflict of interest The authors declare that they have no conflict of interest.

Open Access This article is licensed under a Creative Commons Attribution 4.0 International License, which permits use, sharing, adaptation, distribution and reproduction in any medium or format, as long as you give appropriate credit to the original author(s) and the source, provide a link to the Creative Commons licence, and indicate if changes were made. The images or other third party material in this article are included in the article's Creative Commons licence, unless indicated otherwise in a credit line to the material. If material is not included in the article's Creative Commons licence and your intended use is not permitted by statutory regulation or exceeds the permitted use, you will need to obtain permission directly from the copyright holder. To view a copy of this licence, visit http://creativecommons.org/licenses/by/4.0/.

\section{References}

1. Xia Y, Gates B, Park SH (1999) Fabrication of three-dimensional photonic crystals for use in the spectral region from ultraviolet to near-infrared. J Lightwave Technol 17:1956-1962. https://doi.org/ $10.1109 / 50.802980$

2. Vogel N, Utech S, England GT, Shirman T, Phillips KR, Koay N, Burgess IB, Kolle M, Weitz DA, Aizenberg J (2015) Color from hierarchy: diverse optical properties of micron-sized spherical colloidal assemblies. Proc Natl Acad Sci U S A 112:10845-10850. https://doi.org/10.1073/pnas.1506272112

3. Hellweg T (2009) Towards large-scale photonic crystals with tuneable bandgaps. Angew Chem Int Ed Eng 48:6777-6778. https://doi.org/10.1002/anie.200902742

4. Fischer UC, Zingsheim HP (1981) Submicroscopic pattern replication with visible light. J Vac Sci Technol 19:881-885. https://doi. org/10.1116/1.571227 
5. Cheung CL, Nikolić RJ, Reinhardt CE, Wang TF (2006) Fabrication of nanopillars by nanosphere lithography. Nanotechnology 17:1339-1343. https://doi.org/10.1088/09574484/17/5/028

6. Chau CF, Melvin T (2008) The fabrication of macroporous polysilicon by nanosphere lithography. Nanotechnology 18 : 64012. https://doi.org/10.1088/0960-1317/18/6/064012

7. Plettl A, Enderle F, Saitner M, Manzke A, Pfahler C, Wiedemann S, Ziemann P (2009) Non-close-packed crystals from self-assembled polystyrene spheres by isotropic plasma etching: adding flexibility to colloid lithography. Adv Funct Mater 19:3279-3284. https://doi. org/10.1002/adfm.200900907

8. Velev OD, Jede TA, Lobo RF, Lenhoff AM (1997) Porous silica via colloidal crystallization. Nature 389:447-448. https://doi.org/ 10.1038/38921

9. Park SH, Xia Y (1998) Fabrication of three-dimensional macroporous membranes with assemblies of microspheres as templates. Chem Mater 10:1745-1747. https://doi.org/10.1021/ cm9801993

10. Holland BT, Blanford CF, Do T, Stein A (1999) Synthesis of highly ordered, three-dimensional, macroporous structures of amorphous or crystalline inorganic oxides, phosphates, and hybrid composites. Chem Mater 11:795-805. https://doi.org/10.1021/cm980666g

11. Zhang Z, Pfleiderer P, Schofield AB, Clasen C, Vermant J (2011) Synthesis and directed self-assembly of patterned anisometric polymeric particles. J Am Chem Soc 133:392-395. https://doi.org/10. 1021/ja108099r

12. Panczyk MM, Park J-G, Wagner NJ, Furst EM (2013) Twodimensional directed assembly of dicolloids. Langmuir 29:75-81. https://doi.org/10.1021/la303678f

13. Still T, Sainidou R, Retsch M, Jonas U, Spahn P, Hellmann GP, Fytas G (2008) The "music" of core-shell spheres and hollow capsules: influence of the architecture on the mechanical properties at the nanoscale. Nano Lett 8:3194-3199. https://doi.org/10.1021/ nl801500n

14. Karg M, Hellweg T (2009) Smart inorganic/organic hybrid microgels: synthesis and characterisation. J Mater Chem 19:8714. https://doi.org/10.1039/B820292N

15. Nie Z, Li W, Seo M, Xu S, Kumacheva E (2006) Janus and ternary particles generated by microfluidic synthesis: design, synthesis, and self-assembly. J Am Chem Soc 128:9408-9412. https://doi.org/10. 1021/ja060882n

16. Walther A, Matussek K, Müller AHE (2008) Engineering nanostructured polymer blends with controlled nanoparticle location using Janus particles. ACS Nano 2:1167-1178. https://doi.org/10. $1021 / \mathrm{nn} 800108 \mathrm{y}$

17. Klinger D, Landfester K (2011) Photo-sensitive PMMA microgels: light-triggered swelling and degradation. Soft Matter 7:1426-1440. https://doi.org/10.1039/c0sm00638f

18. Islam MR, Serpe MJ (2014) Polymer-based devices for the labelfree detection of DNA in solution: low DNA concentrations yield large signals. Anal Bioanal Chem 406:4777-4783. https://doi.org/ 10.1007/s00216-014-7867-8

19. Li F, Josephson DP, Stein A (2011) Colloidal assembly: the road from particles to colloidal molecules and crystals. Angew Chem Int Ed Eng 50:360-388. https://doi.org/10.1002/anie.201001451

20. Vogel N, Retsch M, Fustin C-A, del Campo A, Jonas U (2015) Advances in colloidal assembly: the design of structure and hierarchy in two and three dimensions. Chem Rev 115:6265-6311. https://doi.org/10.1021/cr400081d

21. Xu Z, Wang L, Fang F, Fu Y, Yin Z (2016) A review on colloidal self-assembly and their applications. CNANO 12:725-746. https:// doi.org/10.2174/1573413712666160530120807

22. Wijnhoven V (1998) Preparation of photonic crystals made of air spheres in titania. Science 281:802-804. https://doi.org/10.1126/ science. 281.5378 .802
23. You X, Pikul JH, King WP, Pak JJ (2013) Zinc oxide inverse opal enzymatic biosensor. Appl Phys Lett 102:253103. https://doi.org/ $10.1063 / 1.4811411$

24. Xia L, Song J, Xu R, Liu D, Dong B, Xu L, Song H (2014) Zinc oxide inverse opal electrodes modified by glucose oxidase for electrochemical and photoelectrochemical biosensor. Biosens Bioelectron 59:350-357. https://doi.org/10.1016/j.bios.2014.03. 038

25. Müller A (2013) Preparation of polymer nano-foams: templates, challenges and kinetics1st edn. Cuvillier Verlag, Göttingen

26. Strey R, Müller A (2010) Erzeugung nanodisperser Einschlüsse in einer hochviskosen Matrix.(DE102010053064A1)

27. Krause B, Sijbesma HJP, Münüklü P, van der Vegt NFA, Wessling M (2001) Bicontinuous nanoporous polymers by carbon dioxide foaming. Macromolecules 34:8792-8801. https://doi.org/10.1021/ ma010854j

28. Siripurapu S, Coughlan JA, Spontak RJ, Khan SA (2004) Surfaceconstrained foaming of polymer thin films with supercritical carbon dioxide. Macromolecules 37:9872-9879. https://doi.org/10.1021/ ma0484983

29. Grassberger L (2016) Towards cost-efficient preparation of nanoporous materials: formation kinetics, process optimization and material characterization. Dissertation, Verlag Dr. Hut; Universität zu Köln

30. Condo PD, Johnston KP (1994) In situ measurement of the glass transition temperature of polymers with compressed fluid diluents. J Polym Sci B Polym Phys 32:523-533. https://doi.org/10.1002/ polb.1994.090320313

31. Shieh Y-T, Liu K-H (2002). J Polym Res 9:107-113. https://doi. org/10.1023/A:1021189800844

32. Rizvi A, Chu RKM, Park CB (2018) Scalable fabrication of thermally insulating mechanically resilient hierarchically porous polymer foams. ACS Appl Mater Interfaces 10:38410-38417. https:// doi.org/10.1021/acsami.8b11375

33. Wu H-J, Fan J-T, Du N (2009) Porous materials with thin interlayers for optimal thermal insulation. Int J Nonlinear Sci Numer Simul 10. https://doi.org/10.1515/IJNSNS.2009.10.3.291

34. Yi H, Li F, Ning P, Tang X, Peng J, Li Y, Deng H (2013) Adsorption separation of $\mathrm{CO} 2, \mathrm{CH} 4$, and $\mathrm{N} 2$ on microwave activated carbon. Chem Eng J 215-216:635-642. https://doi.org/10. 1016/j.cej.2012.11.050

35. Sekizkardes AK, Kusuma VA, Dahe G, Roth EA, Hill LJ, Marti A, Macala M, Venna SR, Hopkinson D (2016) Separation of carbon dioxide from flue gas by mixed matrix membranes using dual phase microporous polymeric constituents. Chem Commun (Camb) 52: 11768-11771. https://doi.org/10.1039/c6cc04811k

36. Dong K, Sun Q, Meng X, Xiao FS (2017) Strategies for the design of porous polymers as efficient heterogeneous catalysts: from copolymerization to self-polymerization. Catal Sci Technol 7:1028 1039. https://doi.org/10.1039/C6CY02458K

37. Qawasmi Y, Atanasova P, Jahnke T, Burghard Z, Müller A, Grassberger L, Strey R, Bill J, Sottmann T (2018) Synthesis of nanoporous organic/inorganic hybrid materials with adjustable pore size. Colloid Polym Sci 296:1805-1816. https://doi.org/10. 1007/s00396-018-4402-Z

38. Chern C-S, Lin S-Y, Hsu TJ (1999) Effects of temperature on styrene emulsion polymerization kinetics. Polym J 31:516-523. https://doi.org/10.1295/polymj.31.516

39. Gerrens H (1963) Reaktionen der Radikale bei Polymerisationsvorgängen. Ber Bunsenges Phys Chem 67:741753. https://doi.org/10.1002/bbpc.19630670804

40. Krishnan S, Klein A, El-Aasser MS et al (2003) Effect of surfactant concentration on particle nucleation in emulsion polymerization of n -butyl methacrylate. Macromolecules 36:3152-3159. https://doi. org/10.1021/ma021120p 
41. Verwey EJW (1947) Theory of the stability of lyophobic colloids. J Phys Colloid Chem 51:631-636. https://doi.org/10.1021/ j150453a001

42. Gilbert RG, Morrison BR, Napper DH (1991) The status of nucleation models in emulsion polymerization. Polym Mater Sci Eng 64: 308-309

43. Harkins WD (1947) A general theory of the mechanism of emulsion polymerization. J Am Chem Soc 69:1428-1444. https://doi. org $/ 10.1021 / \mathrm{ja} 01198 \mathrm{a} 053$

44. Smith WV, Ewart RH (1948) Kinetics of emulsion polymerization. J Chem Phys 16:592-599. https://doi.org/10.1063/1.1746951

45. Smith WV (1948) The kinetics of styrene emulsion polymerization. J Am Chem Soc 70:3695-3702. https://doi.org/10.1021/ ja01191a045

46. Priest WJ (1952) Partice growth in the aqueous polymerization of vinyl acetate. J Phys Chem 56:1077-1082. https://doi.org/10.1021/ j150501a010

47. Fitch RM (1973) The homogeneous nucleation of polymer colloids. Br Polym J 5:467-483. https://doi.org/10.1002/pi.4980050606

48. Fitch RM (ed) (1980) Polymer colloids II. Springer US, Boston

49. Chern CS, Lin C-H (1999) Using a water-insoluble dye to probe the particle nucleation loci in styrene emulsion polymerization. Polymer 40:139-147. https://doi.org/10.1016/S0032-3861(98) 00232-8

50. Farías-Cepeda L, Herrera-Ordonez J, Saldívar-Guerra E (2010) On the kinetics and particle size polydispersity of the styrene emulsion polymerization using aerosol MA80 and sodium dodecyl sulfate as surfactants. Colloid Polym Sci 288:1401-1409. https://doi.org/10. 1007/s00396-010-2272-0

51. von Nessen K, Karg M, Hellweg T (2013) Thermoresponsive poly(N-isopropylmethacrylamide) microgels: tailoring particle size by interfacial tension control. Polymer 54:5499-5510. https://doi.org/ 10.1016/j.polymer.2013.08.027

52. Paula S, Sues W, Tuchtenhagen J, Blume A (1995) Thermodynamics of micelle formation as a function of temperature: a high sensitivity titration calorimetry study. J Phys Chem 99: 11742-11751. https://doi.org/10.1021/j100030a019

53. Harada M, Nomura M, Kojima H, Eguchi W, Nagata S (1972) Rate of emulsion polymerization of styrene. J Appl Polym Sci 16:811833. https://doi.org/10.1002/app.1972.070160402

54. Hansen FK, Ugelstad J (1979) Particle nucleation in emulsion polymerization. III Nucleation in systems with anionic emulsifier investigated by seeded and unseeded polymerization. J Polym Sci Polym Chem Ed 17:3047-3067. https://doi.org/10.1002/pol.1979. 170171002

55. Chang H-C, Lin Y-Y, Chern C-S, Lin SY (1998) Determination of critical micelle concentration of macroemulsions and miniemulsions. Langmuir 14:6632-6638. https://doi.org/10.1021/ la971109w

56. Chen L-J, Lin S-Y, Chern C-S, Wu SC (1997) Critical micelle concentration of mixed surfactant SDS/NP(EO)40 and its role in emulsion polymerization. Colloids Surf A Physicochem Eng Asp 122:161-168. https://doi.org/10.1016/S0927-7757(96)03851-4

57. Chen Y, Jahanzad F, Sajjadi S (2013) Semicontinuous monomerstarved emulsion polymerization as a means to produce nanolatexes: analysis of nucleation stage. Langmuir 29:5650 5658. https://doi.org/10.1021/la4000654

58. Ramírez AG, López RG, Tauer K (2004) Studies on semibatch microemulsion polymerization of butyl acrylate: influence of the potassium peroxodisulfate concentration. Macromolecules 37: 2738-2747. https://doi.org/10.1021/ma030218g

59. Sosa N, Peralta RD, López RG, Ramos LF, Katime I, Cesteros C, Mendizábal E, Puig JE (2001) A comparison of the characteristics of poly(vinyl acetate) latex with high solid content made by emulsion and semi-continuous microemulsion polymerization. Polymer 42:6923-6928. https://doi.org/10.1016/S0032-3861(01)00157-4
60. Sajjadi S (2001) Particle formation under monomer-starved conditions in the semibatch emulsion polymerization of styrene. I Experimental. J Polym Sci A Polym Chem 39:3940-3952. https:// doi.org/10.1002/pola.10031

61. Ni KF, Shan GR, Weng ZX, Sheibat-Othman N, Fevotte G, Lefebvre F, Bourgeat-Lami E (2005) Synthesis of hybrid core -shell nanoparticles by emulsion (co)polymerization of styrene and $\gamma$-methacryloxypropyltrimethoxysilane. Macromolecules 38 : 7321-7329. https://doi.org/10.1021/ma050334e

62. Norakankorn C, Pan Q, Rempel GL et al (2009) Factorial experimental design on synthesis of functional core/shell polymeric nanoparticles via differential microemulsion polymerization. J Appl Polym Sci 25:NA-NA. https://doi.org/10.1002/app.31493

63. Atanasova P, Stitz N, Sanctis S, Maurer JHM, Hoffmann RC, Eiben S, Jeske H, Schneider JJ, Bill J (2015) Genetically improved monolayer-forming tobacco mosaic viruses to generate nanostructured semiconducting bio/inorganic hybrids. Langmuir 31:38973903. https://doi.org/10.1021/acs.langmuir.5b00700

64. Princen HM, Zia IYZ, Mason SG (1967) Measurement of interfacial tension from the shape of a rotating drop. J Colloid Interface Sci 23:99-107. https://doi.org/10.1016/0021-9797(67)90090-2

65. Schwan M, Kramer LGA, Sottmann T, Strey R (2010) Phase behaviour of propane- and $\mathrm{scCO}(2)$-microemulsions and their prominent role for the recently proposed foaming procedure POSME (principle of supercritical microemulsion expansion). Phys Chem Chem Phys 12:6247-6252. https://doi.org/10.1039/b909764c

66. Provencher SW (1982) A constrained regularization method for inverting data represented by linear algebraic or integral equations. Comput Phys Commun 27:213-227. https://doi.org/10.1016/00104655(82)90173-4

67. Richard D, Ferrand M, Kearley GJ (1996) Analysis and visualisation of neutron-scattering data. J Neutron Res 4:33-39. https://doi. org/10.1080/10238169608200065

68. Viguir G, Girardot R, Perez J (2016) Foxtrot 3.3.4

69. Zhang F, Ilavsky J, Long GG, Quintana JPG, Allen AJ, Jemian PR (2010) Glassy carbon as an absolute intensity calibration standard for small-angle scattering. Metall Mater Trans A 41:1151-1158. https://doi.org/10.1007/s11661-009-9950-x

70. Guinier A, Fournet G (1955) Small-angle scattering of X-rays. Wiley

71. Kaler EW (1995) Small — angle scattering from complex fluids. In: Brumberger $\mathrm{H}$ (ed) Modern aspects of small-angle scattering, vol 145. Springer Netherlands, Dordrecht, pp 329-353

72. Chern CS (2006) Emulsion polymerization mechanisms and kinetics. Prog Polym Sci 31:443-486. https://doi.org/10.1016/j. progpolymsci.2006.02.001

73. von Szyszkowski B (1908) Experimentelle Studien über kapillare Eigenschaften der wässerigen Lösungen von Fettsäuren. Z Phys Chem 64U. https://doi.org/10.1515/zpch-1908-6425

74. Langmuir I (1917) The constitution and fundamental properties of solids and liquids. II liquids. 1. J Am Chem Soc 39:1848-1906. https://doi.org/10.1021/ja02254a006

75. Nusselder JJH, Engberts JBFN (1992) Toward a better understanding of the driving force for micelle formation and micellar growth. J Colloid Interface Sci 148:353-361. https://doi.org/10.1016/00219797(92)90174-K

76. Pedersen JS (1994) Determination of size distribution from smallangle scattering data for systems with effective hard-sphere interactions. J Appl Crystallogr 27:595-608. https://doi.org/10.1107/ S0021889893013810

77. Baxter RJ (1970) Ornstein-Zernike relation and Percus-Yevick approximation for fluid mixtures. J Chem Phys 52:4559-4562. https://doi.org/10.1063/1.1673684

78. Regnaut C, Ravey JC (1989) Application of the adhesive sphere model to the structure of colloidal suspensions. J Chem Phys 91: 1211-1221. https://doi.org/10.1063/1.457194 
79. Menon SVG, Manohar C, Rao KS (1991) A new interpretation of the sticky hard sphere model. J Chem Phys 95:9186-9190. https:// doi.org/10.1063/1.461199

80. Weyerich B, Brunner-Popela J, Glatter O (1999) Small-angle scattering of interacting particles. II Generalized indirect Fourier transformation under consideration of the effective structure factor for polydisperse systems. J Appl Crystallogr 32:197-209. https://doi. org/10.1107/S0021889898011790

81. Verlet L, Weis J-J (1972) Perturbation theory for the thermodynamic properties of simple liquids. Mol Phys 24:1013-1024. https://doi. org/10.1080/00268977200102111

82. Henderson D, Grundke EW (1975) Direct correlation function: hard sphere fluid. J Chem Phys 63:601-607. https://doi.org/10. 1063/1.431378

83. Ostwald W (1900) Über die vermeintliche Isomerie des roten und gelben Quecksilberoxyds und die Oberflächenspannung fester Körper. Z Phys Chem:495-503. https://doi.org/10.1515/zpch1900-3431

84. Egelhaaf S, Olsson U, Schurtenberger P, Morris J, Wennerström H (1999) Quantitative measurements of Ostwald ripening using timeresolved small-angle neutron scattering. Phys Rev E 60:56815684. https://doi.org/10.1103/PhysRevE.60.5681

85. Smoluchowski M (1917) Mathematical theory of the kinetics of the coagulation of colloidal solutions. Z Phys Chem 19:129-135

86. Meakin P (1991) Steady state droplet coalescence. Physica A 171: 1-18. https://doi.org/10.1016/0378-4371(91)90353-E
87. Mosanenzadeh SG, Naguib HE, Park CB et al (2014) Development of polylactide open-cell foams with bimodal structure for highacoustic absorption. J Appl Polym Sci 131:n/a-n/a. https://doi.org/ 10.1002/app.39518

88. Zhang C, Zhu B, Li D, Lee LJ (2012) Extruded polystyrene foams with bimodal cell morphology. Polymer 53:2435-2442. https://doi. org/10.1016/j.polymer.2012.04.006

89. Bao J-B, Weng G-S, Zhao L, Liu ZF, Chen ZR (2014) Tensile and impact behavior of polystyrene microcellular foams with bi-modal cell morphology. J Cell Plast 50:381-393. https://doi.org/10.1177/ 0021955X14525960

90. Lipowsky P, Hedin N, Bill J, Hoffmann RC, Ahniyaz A, Aldinger F, Bergström L (2008) Controlling the assembly of nanocrystalline $\mathrm{ZnO}$ films by a transient amorphous phase in solution. J Phys Chem C 112:5373-5383. https://doi.org/10.1021/jp077201a

91. Atanasova P, Hoffmann RC, Stitz N, Sanctis S, Burghard Z, Bill J, Schneider JJ, Eiben S (2019) Engineered nanostructured virus/ZnO hybrid materials with dedicated functional properties. Bioinspir Biomim Nan 8:2-15. https://doi.org/10.1680/jbibn.18.00006

92. Stitz N, Eiben S, Atanasova P, Domingo N, Leineweber A, Burghard Z, Bill J (2016) Piezoelectric templates - new views on biomineralization and biomimetics. Sci Rep 6:26518. https://doi. org $/ 10.1038 /$ srep26518

Publisher's note Springer Nature remains neutral with regard to jurisdictional claims in published maps and institutional affiliations. 